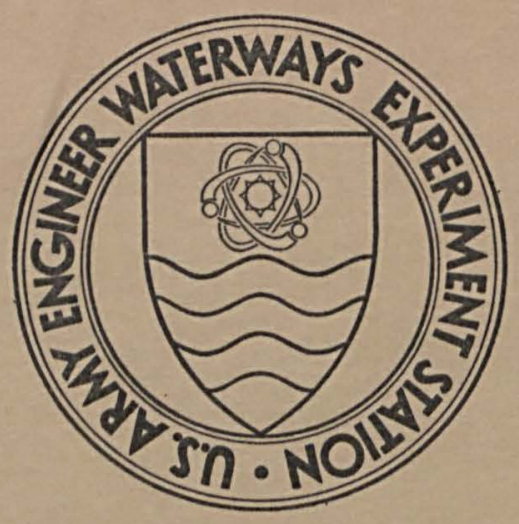

MISCELLANEOUS PAPER C-72-5

\title{
EXAMINATION OF CEMENT PASTES HYDRATED PHASES, AND SYNTHETIC PRODUCTS BY X-RAY DIFFRACTION \\ by
}

K. Mather
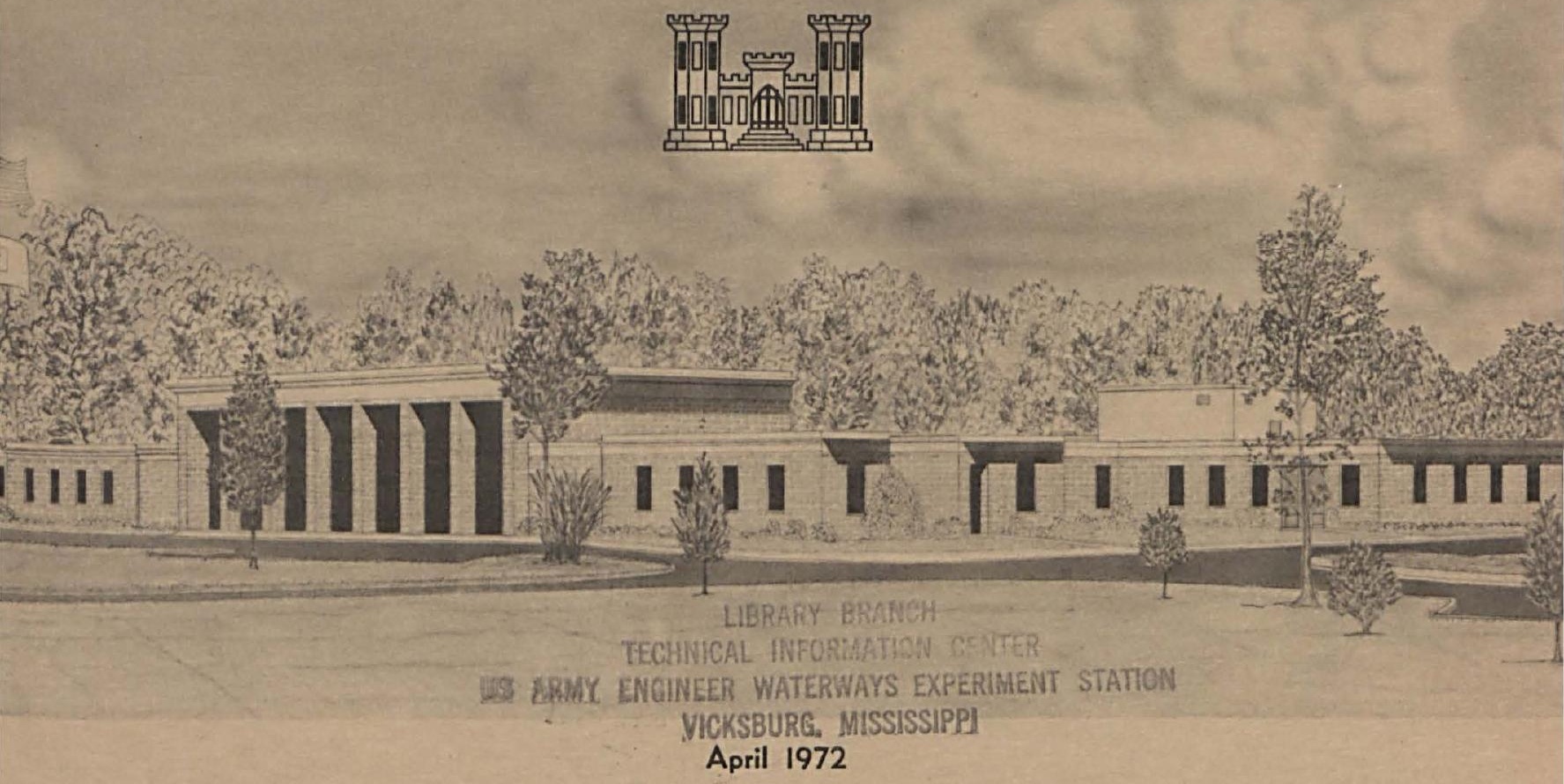

Sponsored by Office, Chief of Engineers, U. S. Army

Conducted by U. S. Army Engineer Waterways Experiment Station, Vicksburg, Mississippi 


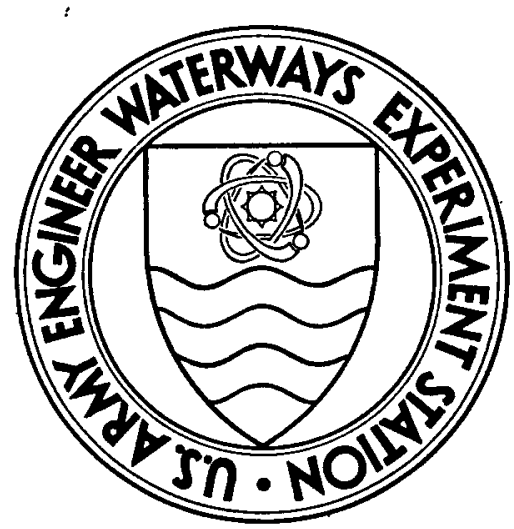

MISCELLANEOUS PAPER C-72-5

\section{EXAMINATION OF CEMENT PASTES HYDRATED PHASES, AND SYNTHETIC PRODUCTS BY X-RAY DIFFRACTION \\ by \\ K. Mather}

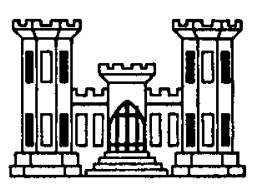

April 1972

Sponsored by Office, Chief of Engineers, U. S. Army

Conducted by U. S. Army Engineer Waterways Experiment Station, Vicksburg, Mississippi 
Cop.2 This report includes the results of a cooperative program on X-ray diffraction studies of cement pastes, hydrated phases, and synthetic hydrates. The work reported formed a part of a cooperative research program sponsored by the Committee on Basic Research Pertaining to Portland Cement and Concrete of the Highway Research Board. The program on evaluation of methods of identifying phases in cement pastes was initiated by $\mathrm{Dr}$. George Kalousek while Dr. R. C. Mielenz was chairman of the committee, and was conducted by a task group headed by Dr. Kalousek while Dr. W. L. Dolch was chairman of the committee. Dr. Dolch became chairman of the task group in 1969.

Under the Engineer Studies Program of the Office, Chief of Engineers (ES Item 614.2) the Concrete Division of the U.S. Army Engineer Waterways Experiment Station took part in the cooperative X-ray diffraction work. The work was done under the supervision of Thomas B. Kennedy, Bryant Mather, and R. V. Tye, Jr. The X-ray diffraction was done by Wilbur I. Luke, Delbert E. Day, and Alan D. Buck. The other cooperating laboratories provided. reports of their results to Katharine Mather who prepared the report as a section of the report on the whole project.

Directors of the WES while this work was going on were COL Alex G. Sutton, CE, COL John R. Oswalt, Jr., CE, COL Levi A. Brown, CE, and COL Ernest D. Peixotto, CE. Mr. Joseph B. Tilfany, Jr., and Mr. Frederick R. Brown were Technical Directors. 
$\underline{\text { Page }}$

Foreword . . . . . . . . . . . . . . . . . . 1i1

Summary . . . . . . . . . . . . . . . . . . . vil

Introduction . . . . . . . . . . . . . . . . . 1

Participants . . . . . . . . . . . . . . . 1

Approach . . . . . . . . . . . . . . . . . . 2

Samples - cement pastes . . . . . . . . . . . . 2

Samples - hydrates and synthetic products . . . . . . . 3

Instrumentation . . . . . . . . . . . . . . . . 3

Examination of pastes . . . . . . . . . . . . . . 4

Results . . . . . . . . . . . . . . . . . 4

Examination of hydrates and synthetic products . . . . . . 12

Discussion: detection of $\mathrm{C}-\mathrm{S}-\mathrm{H}$ gel . . . . . . . . . 15

Problems in Identification of paste constituents . . . . . 16

Identification of platy hexagonal hydrated calcium aluminate with and without additional anions . . . . . . . . . 18

Conclusion . . . . . . . . . . . . . . . . 20

REFERENCES . . . . . . . . . . . . . . . . . 22

TABLES $\quad 1-19$

FIGURES 1-7 


\section{Summary}

Pastes of three cements were examined by X-ray diffraction at five ages in seven laboratories. Six of the laboratories used X-ray diffractometers and one used a focusing camera of the Guinier type. Six laboratories examined hydrated phases and synthesized hydrates. This is the first cooperative program in X-ray diffraction of portland cement pastes and synthetic hydrates of which we have knowledge.

Pastes of all three cements were mixed at water-cement ratios of 0.35 and 0.65 and were examined after hydration had been stopped at ages of $1,7,28,90$, and 365 days. Pastes of a Type I cement at 0.35 water-cement ratio contained ettringite, tetracalcium aluminate monosulfate-12-hydrate, calcium hydroxide, calcium silicate hydrate gel, and residual cement constituents. Tetracalcium aluminate monosulfate-12-hydrate was detected at 7 days and increased thereafter at the expense of ettringite. Compositions of pastes of this cement at 0.65 water-cement ratio were similar to those of the pastes of 0.35 water-cement ratio; the sequences of hydrates appearing and Increasing, and cement constituents diminishing and in some instances disappearing, were more conspicuous. The sequence of development and constituents present in pastes of a white cement at the two water-cement ratios resembled the Type I pastes. Pastes of a third cement containing no tricalcium aluminate formed less ettringite than pastes of the other two cements; ettringite persisted to one year; 
tetracalcium aluminate monosulfate-12-hydrate was detected only in trace amounts.

Spacings present in hydrated alite, hydrated $\beta-C_{2} S$, tetracalcium aluminate hemicarbonate-12-hydrate, tetracalcium aluminate carbonate-11-hydrate, tetracalclum aluminate monosulfate-12-hydrate, unstable tetracalcium aluminate10.5-hydrate, and ettringite, are reported. 


\section{Introduction}

One of the techniques used to identify hydration products in cement pastes, hydrated phases, and synthetic products was X-ray diffraction. X-ray diffraction has been extensively and successfully used to study materials of these types by Flint, McMurdie, and Wells, (1) Taylor, $(2,4)$ Heller and Taylor, (3) Turriziani and colleagues, $(5,6,7)$ Kalousek, (8) Midgley, (9) Kantro, Copeland, and Anderson, (10) and many others.

The work reported here is the first cooperative investigation by X-ray diffraction of pastes and synthesized hydrates of which we are aware. All of the participants performed a service to the community of cement and concrete research. Participants

The participating laboratories are listed below. They are identified in subsequent tables by numbers that do not correspond to the listed order.

a. Building Research Station, Garston, Watford, Herts., UK.

b. Ideal Cement Company, Fort Collins, Colo., USA.

c. Portland Cement Association Research and Development Laboratories, Skokie, I11., USA.

d. Ube Kosan Company, Ltd., Central Research Laboratory, 1970-6 Ohaza Kogushi, Uke-Shi, Yamaguchi-Ken, Japan. 
e. Universal Atlas Cement Division, Buffington, Ind., USA.

f. Engineering Materials Laboratory, University of California, Berkeley, Calif., USA.

g. Waterways Experiment Station, Concrete Division, Vicksburg, Miss., USA. Approach

Participants were asked to make their examinations and report their data as they usually did, and if they wished to do so, to modify their procedures. As a consequence of these instructions, procedures differed widely from laboratory to laboratory. In some cases procedures were modified within a laboratory in the course of the program. While the absence of prescribed procedures led to differences in results, the opportunity to compare results obtained by following different procedures with different instruments was most valuable. Samples - cement pastes

The Research Laboratories of the Universal Atlas Cement Division prepared and distributed cement pastes (table 1) which were examined by six of the participants. Pastes were prepared at water-cement ratios of 0.35 and 0.65 , with three cements: a type I cement of average composition, a white cement, and a zero $\mathrm{C}_{3} \mathrm{~A}$ cement. The pastes were cured at $75 \mathrm{~F}$ for $1,7,28,90$, and 365 days. Twenty-eight of the 30 paste samples contained 0.0 to 0.2 percent $\mathrm{CO}_{2}$, the other two 0.4 to 0.5 percent $\mathrm{CO}_{2}$. Hydration was terminated at the selected 
age by crushing the paste to pass a No. 20 sieve, washing the crushed sample in acetone, and then immediately subjecting it to suction filtration. The sample was then dried in vacuum for $24 \mathrm{hr}$ at $40-50 \mu \mathrm{m} \mathrm{Hg}$.

The seventh participant later prepared pastes at the same two water-cement ratios, and cured them for $1,3,7$, 14, 28, and 92 days. Each paste was examined as a wet lapped slice and as a hard-dried powder. The results obtained were very similar to those obtained by examining the pastes originally distributed. Samples - hydrates and synthetic products

Samples of hydrates of alite and $\beta-C_{2} S$, and of synthetic products (table 1 ) were examined by most of the participants (table 2). The preparation of the calcium aluminate monosulfate used in this program has been described.

\section{Instrumentation}

The instruments used by the cooperating laboratories are identified in table 3. Five of the diffractometers were essentially standard models, but the sixth was equipped with a fine-focus X-ray tube, curved-crystal monochromator, and a Geiger-counter detector. The seventh laboratory used a focusing camera (of the Guinier type) with monochromatic copper radiation because they had found it more able to detect weak lines, and thus to detect small quantities, than their diffractometer. Operating conditions reported are shown in tables $4 a$ and $4 b$. 


\section{Examination of pastes}

X-ray diffraction was one of the methods used to Identify and characterize hydration products in pastes. The specific intentions in the X-ray portion of the program included determining the sequence of hydration products developed in the three cements and the number and kinds of products detected in different laboratorles with different instrumentation.

The available hydrated alite and belite, and synthetic products offered the participants the opportunity of examining carefully prepared samples of substances that are present or may be present in mixture in pastes and concretes. It also presented an opportunity for comparing effects of conditions during storage and examination on some of the substances. Results

As previously stated no instructions on procedure were included, with the result that in some of the participating laboratories the samples were subjected to routine examination while in others procedures were adjusted carefully to the samples to maximize the information obtained. The previous experience of the operators in examining hydrated cement pastes ranged from none to several years experience; the expertise of the X-ray operators also ranged widely. Because of the variations in approach, experience, and expertise, the detail obtained and reported also differed considerably from laboratory to laboratory. A11 of these variations should 
be borne in mind in studying the tables of constituents identified in the cement pastes.

One of the laboratories ranked the constituents reported as follows:

$$
\begin{aligned}
\mathrm{C}= & \text { Compound certainly present (at least three lines } \\
& \text { detected). } \\
\mathrm{P}= & \text { Compound probably present (at least two strong } \\
& \text { 1ines detected; others overlapped). } \\
\mathrm{D}= & \text { Presence of compound can be doubted (one or two } \\
& \text { Iines just detectable; others overlapped). } \\
\mathrm{U}= & \text { Undetected. }
\end{aligned}
$$

\begin{tabular}{|c|c|c|}
\hline $\begin{array}{l}\text { Ettringite } \\
\mathrm{C}_{4} \mathrm{~A} \bar{S}_{12} \mathrm{H}_{12} \\
\mathrm{C}_{4} \mathrm{~A} \bar{C}_{0} . \mathrm{H}_{12} \\
\mathrm{C}-\mathrm{A} \text { hydrate } \\
\mathrm{C}_{4} \mathrm{~A} \overline{\mathrm{C}} \mathrm{H}_{11} \\
\text { Calcium hydroxide } \\
\text { Hydrogarnet } \\
\mathrm{C}-\mathrm{S}-\mathrm{H}\end{array}$ & $\begin{array}{l}9.8 \\
8.9 \\
8.2 \\
- \\
7.7 \\
4.90,2.63 \\
5.06,2.54 \\
3.03,1.82\end{array}$ & $\begin{array}{l}9.8 \\
8.9 \\
8.2 \\
7.9 \\
7.7 \\
4.9 \\
2.54 \\
3.04,2.98\end{array}$ \\
\hline $\begin{array}{l}\text { Alite } \\
\text { Belite } \\
\mathrm{C}_{3} \mathrm{~A} \\
\text { Aluminoferrite SS } \\
\text { Mg0 } \\
\text { Calcite }\end{array}$ & $\begin{array}{l}2.97,1.76 \\
2.88 * \\
2.69 \\
7.3,2.65 \\
2.10 \\
* *\end{array}$ & $\begin{array}{l}2.79 \\
2.88 \\
2.69 \\
7.3,2.66 \\
2.10 \\
2.29\end{array}$ \\
\hline
\end{tabular}

Two listed the interplanar spacings which each regarded as diagnostic of the constituent Identified:

$$
\frac{\text { Interp lanar Spacings, } \mathrm{d}, \mathrm{m} \times 10^{-10}}{\text { Laboratory } 3}
$$

* Line interfered with by $\mathrm{C}_{4} \mathrm{AS}_{\mathrm{S}} \mathrm{H}_{12}$

** With Cement No. 1, 2.10, 2.28; with cement No. 2, 3.88, $2.28,2.10$; with cement No. $3,3.03,2.28,2.10$. 
Table 5, Characteristic Spacings of Constituents of Portland Cement Pastes, is a modified compllation to show useful spacings and over laps and interferences.

The compositions of the pastes examined in the program are shown in tables 6 through 11 in terms of the constituents reported by the participating laboratorles as present at each age of the pastes. Partial X-ray diffraction charts are shown in rigs. 1 through 6 .

A11 of the participating laboratories reported the presence of calcium hydroxide in pastes of all three cements at both water-cement ratios at all ages. Ettringite was reported in pastes of all three cements at both water-cement ratios at all ages with one exception; none was reported in pastes of cement No. 1 of 0.65 water-cement at 365 days (figs. 1-3). $\mathrm{C}_{4} \mathrm{AS} \mathrm{H}_{12}$ was reported in pastes of al1 three cements at 0.35 water-cement ratio at al1 ages with two exceptions: none was reported in pastes of cement No. 1 or No. 3 at 1 day; only two laboratories reported it in pastes of cement No. 3 . Both indicated that it was present in small amounts only. In pastes of 0.65 water-cement ratio, $\mathrm{C}_{4} \mathrm{AS} \mathrm{SH}_{12}$ was reported from cement No. 1 at al1 ages, and from cement Nos. 2 and 3 at a11 ages except 1 day. Again, only two laboratories reported it from pastes of cement No. 3. Judging by the number of laboratories reporting its presence in pastes of cement No. 2 with 0.65 water-cement ratio at ages greater than 1 day, these pastes contained more $\mathrm{C}_{4} \mathrm{ASH}_{12}$ than any others in the 
program (figs. 1-5). Hydrogarnet was reported by only two laboratories; one reported it in pastes of cement No. 1 with 0.35 water-cement ratio at ages of 7 through 365 days; in pastes of the same cement with water-cement ratio of 0.65 one laboratory reported it at 1 day and two at all later ages. Apparently it formed more abundantly or more recognizably in pastes with the higher water cement ratio (figs. 1 and 4). In pastes of cement No. 2 with 0.35 water-cement ratio it was reported by one laboratory at 365 days. In pastes of cement No. 3 with 0.65 water-cement ratio it was reported by one laboratory at 1 and 7 days and not thereafter. Kantro, Copeland, and Anderson ${ }^{(10)}$ reported hydrogarnet in pastes of cements of several types; it has also been reported from field concretes.

C-S-H was reported in pastes of all cements at both water-cement ratios by one to five laboratories.

Three other hydrates were reported: $\mathrm{C}_{4} \mathrm{ACH}_{11}, \mathrm{C}_{4} \mathrm{AH}_{\mathrm{x}}$, and $\mathrm{C}_{3} \mathrm{AH}_{6}$. The first was reported at one or more ages in pastes with both water-cement ratios from cements No. 1 and 2 ; it was not reported from pastes of cement No. 3 except in pastes of 0.65 water-cement ratio at 365 days. It appears that when it formed it formed more abundantly from pastes of 0.65 water-cement ratio. It was least abundant in pastes of cement No. 3 in which less ettringite developed than in pastes of cements 1 and $2 . \mathrm{C}_{4} \mathrm{AH}_{x}$ characterized by a line at $29 \mathrm{~A}$ 
was reported by two laboratories at one or more ages in the pastes of 0.35 water-cement ratio of all three cements, and by one in the pastes of 0.65 water-cement ratio of cements No. 2 and 3. Another laboratory reported it from pastes of cement No. 1 of 0.65 water-cement ratio at two ages. One laboratory reported $\mathrm{C}_{3} \mathrm{AH}_{6}$ in paste of cement No. 1 with $0.35 \mathrm{w} / \mathrm{c}$ at one age as doubtful.

Unhydrated constituents of al1 cements were reported. Alite was reported from a11 pastes at all ages, but in pastes of 0.65 water-cement ratio the number of laboratories reporting it fell off sharply at 365 days. Belite was also reported from all pastes at all ages. Aluminoferrite solid solution was reported in pastes of cements 1 and 3 at both water-cement ratios at all ages. MgO was reported only from Cement No. 1 in pastes of both water ratios at all ages. $C_{3} A$ was reported in pastes of cement 1 at $0.35 \mathrm{w} / \mathrm{c}$ at all ages, and through 28 days in pastes of $0.65 \mathrm{w} / \mathrm{c}$. It was reported through 28 days in pastes of cement No. 2 at 0.35 water-cement ratio and through 90 days in pastes at 0.65 water-cement ratio. One laboratory reported calcite at one or more ages in pastes of al1 three cements at 0.65 water-cement ratio. One laboratory compared diffractometer traces made with the same operating conditions for each cement at each watercement ratio and age to see what effects of water-cement ratio could be detected. With logarithmic operation of the rate 
meter and full scale deflection equal to 4000 counts per sec, beam slit $1 \mathrm{deg}, 3 \mathrm{deg}$ beam slit as Soller, and 0.2 deg detector s11t:

(1) Background levels in pastes of cement No. 1 and No. 2 were lower than in pastes of cement No. 3 .

(2) The heights of the calcium hydroxide peaks at 18 and 34 deg two-theta increased in pastes cured longer than 1 day, and were greater in the pastes of higher watercement ratio. The net intensity of these peaks was less in cement No. 3 than in pastes of the other two cements.

(3) Age by age, the pastes of 0.35 water-cement ratio contained more conspicuous remains of the structure of the unhydrated cement.

(4) In pastes of cement No. $1 \mathrm{CH}$ was more abundant in the pastes of $0.65 \mathrm{w} / \mathrm{c}$. Ettringite was more abundant in pastes at 0.65 water content at 1 and 7 days, less abundant at 28,90 , and 365 days. $\mathrm{C}_{4} \mathrm{As} \mathrm{SH}_{12}$ was more abundant at 7,28 , 90 , and 365 days in pastes of 0.65 water-cement ratio. Hydrogarnet increased from 7 days through 365 days in the pastes of 0.65 water-cement ratio. If the lines at $5.94,2.97$, and $1.76 \mathrm{~A}$ are taken as unequivocal evidence of the presence of alite, the $5.94 \mathrm{~A}$ line was recognizable in the pastes of $0.35 \mathrm{w} / \mathrm{c}$ through 28 days but was only present at 1 day in those of $0.65 \mathrm{w} / \mathrm{c}$; the line at $2.97 \mathrm{~A}$ is recognizable but very very weak at 365 days, and the line at $1.76 \mathrm{~A}$ through 
365 days in the pastes of lower w/c. In the pastes of 0.65 water-cement ratio 1.76 is perceptible through 28 days but 2.97 is not. The 2.70 line of $C_{3} \mathrm{~A}$ is probably present at 7 days, not thereafter, in the pastes of 0.65 water-cement ratio; in the $0.35 \mathrm{w} / \mathrm{c}$ pastes it is present at 28 days but thereafter only the aluminoferrite line at 2.683 can be recognized. At both water-cement ratios, Mg0 decreased noticeably from 1 to 7 days but did not change perceptibly thereafter. In the pastes of both water-cement ratios the 2.88 peak appeared to increase from 7 days over what it was at 1 day, showing the presence of $\mathrm{C}_{4} \mathrm{~A} \overline{\mathrm{S}} \mathrm{H}_{12}$ and rendering the peak only dubious evidence of belite. The aluminoferrite line at $12 \mathrm{deg}$ two-theta was present at a11 ages in pastes of 0.35 and 0.65 .water-cement ratio.

(5) In pastes of cement No. 2 with both watercement ratios the apparent intensities of the calcium hydroxide line at $4.92 \mathrm{~A}$ increase with age. The ettringite lines are more intense in the pastes of 0.65 water-cement ratio through 90 days; $\mathrm{C}_{4} \mathrm{AS}^{\mathrm{S}} \mathrm{H}_{12}$ is present at 1 day in the pastes of 0.65 water-cement ratio and increases thereafter to 90 days, diminIshing apparently at 365 days. The 2.88 line diminishes from $I$ day through 90 days and then increases at 365 in the pastes of 0.65 water-cement ratio. In the pastes of 0.35 watercement ratio, the 2.88 Ine increases from 7 days, showing the increase in $\mathrm{C}_{4} \mathrm{~A} \bar{S}_{12}$ but making the spacing dubious as evidence of belite. The $\mathrm{C}_{3} \mathrm{~A}$ line at $2.70 \mathrm{~A}$ persisted to 
7 days in the pastes of lower water-cement ratio, and was detectable at 1 day in the 0.65 water-cement ratio paste. In the paste of lower water-cement ratio the $2.97 \mathrm{~A}$ and $1.76 \mathrm{~A}$ lines of alite persisted at 365 days; in the paste of higher water content, the 2.97 line was not recognized at 90 days, the $1.76 \mathrm{~A}$ 1ine was detectable at 90 but not at 365 days.

(6) Pastes of cement No. 3 at both water contents contained ettringite at all ages; $\mathrm{C}_{4} \mathrm{ASH}_{12}$ could be detected in pastes cured more than 1 day but it was less conspicuous than the ettringite. The belite line at $2.88 \mathrm{~A}$ was barely perceptible at 7 days in the paste of higher water content but persisted until 28 days in the paste of lower water content. The alite lines at 2.97 and $1.76 \mathrm{~A}$ were detected at 365 days in the paste of lower water content; the $2.97 \mathrm{~A}$ line was detected at 28 days and the $1.76 \mathrm{~A}$ line was barely detected at 90 days in the paste of higher water content. Aluminoferrite lines including the weak line at $3.66 \mathrm{~A}$ persisted at 365 days in pastes of both water contents.

Table 12 shows scaled intensities of characteristic peaks of ettringite, $\mathrm{C}_{4} \mathrm{AS} \mathrm{SH}_{12}$, and calcium hydroxide of pastes of a11 three cements at 0.65 water-cement ratio. 
Examination of hydrates and synthetic products

Two reports of spacings of hydrated alite cured 5.3 years appear in table 13. It contalned calcium hydroxide and C-S-H gel represented : broad lines at 3.07 and $1.82 \mathrm{~A}$ (fig. 7). Laboratory 6 reported a line at 2.97 not resolved by laboratory 3 and identified it as another $\mathrm{C}-\mathrm{S}-\mathrm{H}$ gel spacing. Laboratory 3 described the spacing at $3.066 \mathrm{~A}$ as a broad asymmetric hump from about 26 to 38 two-theta, rising steeply from 28 to 29.3 and then sloping gently to background at 38 . The spacing at $1.819 \mathrm{~A}$ was described as a symmetrical hump about 2.5 two-theta broad at the background leve1. No residual lines of unhydrated alite were found by any of the participants and the third spacing of near-amorphous $\mathrm{C}-\mathrm{S}-\mathrm{H}$ at ibout 2.80 was apparently inconspicuous.

The hydrated $3-\mathrm{C}_{2} \mathrm{~S}$ (table 14) contained less calcium hydroxide, a large number of spacings characteristic of unhydrated $3-\mathrm{C}_{2} \mathrm{~S}$, and the spacing at $2.97 \mathrm{~A}$ (reported by three laboratories) identified by laboratory 6 as $\mathrm{C}-\mathrm{S}-\mathrm{H}$ gel, as well as spacings at 3.05 or $3.06,2.815(?)$ or 2.79 , and 1.819 or 1.825 , characteristic of almost amorphous C-S-H ge1.

Three hexagonal platy calcium aluminate hydrates with additional anions were examined by most of the participating laboratories. Results are reported in tables 15 through 17 .

$\mathrm{C}_{4} \mathrm{~A} \bar{C}_{0.5^{\mathrm{H}}} \mathrm{H}_{12}$ was examined in six laboratories; in four of these the sample contained $\mathrm{C}_{4} \mathrm{~A} \overline{\mathrm{C}}_{0 .} 5^{\mathrm{H}} 10$ as we 11 as $\mathrm{C}_{4} \mathrm{~A} \overline{\mathrm{C}}_{0.5} \mathrm{H}_{12}$. It also contained a small amount of $\mathrm{C}_{3} \mathrm{AH}_{6}$. Dosch and zur Strassen ${ }^{(13)}$ obtained $\mathrm{C}_{4} \mathrm{AC}_{0.5^{\mathrm{H}}} \overrightarrow{\mathrm{H}}_{2}$ with a basal spacing of $8.2 \mathrm{~A}$ at 81 percent relative humidity and a dehydration product with a basal spacing of $7.7 \mathrm{~A}$ and a water content 
recorded as $9 \mathrm{H}_{2} \mathrm{O}$ at 11 percent relative humidity; it does not appear that they investigated the production of the partial dehydrated phase at higher humidities. Since the 7.7-A phase appeared in four laboratories it seems probable that dehydration of the $8.2-A$ phase begins at relative humidities above 11 percent. Dosch, Keller, and zur Strassen (14) have found that the $\mathrm{CO}_{3}$ content of the material described by Seligmann and Greening $(15)$ as $\mathrm{C}_{3} \mathrm{~A} \cdot 1 / 2 \mathrm{Ca}(\mathrm{OH})_{2} \cdot 1 / 2 \mathrm{CaCO}_{3} \cdot \mathrm{H}_{\mathrm{X}}$ (equal to $\mathrm{C}_{4} \mathrm{AC}_{0 .} \mathrm{H}_{\mathrm{X}}$ ), ranges from 0.25 to 0.5 , which reconciles the previous disparity of views on the carbonate content of the substance.

Table 16 shows spacings of $\mathrm{C}_{4} \mathrm{ACH}_{11}$ reported by two laboratories. Very small amounts of $\mathrm{C}_{3} \mathrm{AH}_{6}$ were reported by four of the six laboratories that examined this sample. There was no indication that any dehydration stage of $\mathrm{C}_{4} \mathrm{ACH}_{11}$ was present.

Spacings of tetracalcium aluminate monosulfate-12-hydrate $\left(\mathrm{C}_{4} \mathrm{AS} \mathrm{H}_{12}\right)$ recorded by two laboratories are shown in table 17. Five laboratories examined this sample; aIl found a very smali amount of ettringite with the monosulfate. Partial dehydration of the sample occurred in three of the laboratories; in two of them it took place because the sample was stored or examined at reduced relative humidity but in the third it apparently resulted from laboratory ambient relative humidity. In one laboratory it was stored over $\mathrm{CaCl}_{2}$ (at a relative humidity of 33 percent) for three days before X-ray examination. In another it was first examined in a static nitrogen atmosphere--in which it was partly dehydrated--and subsequent ly rehydrated by storing it in a sealed container for one week over $\mathrm{Mg}\left(\mathrm{NO}_{3}\right)_{2} \cdot 6 \mathrm{H}_{2} \mathrm{O}$ which produces a relative humidity over 50 percent at 
about $23 \mathrm{C}(55 \% \mathrm{r} . \mathrm{h}$. at $18 \mathrm{C}, 21.5 \%$ at $31 \mathrm{C})$ which returned a 11 of the sample to the 12-hydrate condition.

Sample 40 was prepared to have the composition $\mathrm{C}_{4} \mathrm{AH}_{10.5}$. As examined by Five laboratories it appeared to have been unstable. Reports from three of the laboratories are shown in table 18, with interpretations provided by the writer. A summary of all five reports follows:

\section{Laboratory}

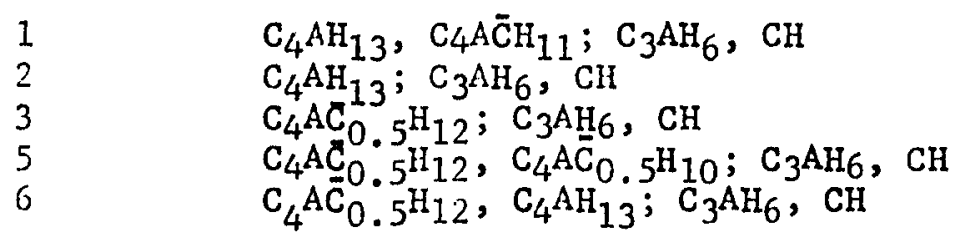

Carbonation and dehydration affected the portions of the sample differently in Sour of the laboratories.

Sample 41, ettringite produced at the National Bureau of Standards, was examined by five laboratories; results from two appear in table 19. One laboratory examined another sample of ettringite prepared by the Portland Cement Association Research and Development Laboratories and found it comparable to the sample prepared by the National Bureau of Standards with the addition of two or three weak lines. Card 9-414, Ettringite, in the Powder Diffraction File (16) 1 ists spacings from 9.73 to $1.768 \mathrm{~A}$, including a total of 50 . Participants in this program reported 21 to 54 spacings in this range including a few not shown on the card which are believed to represent one or more additional constituents of the sample. Hoore and Taylor(17) have described the structure of 
naturally occurring ettringite from Scawt Hi11. The crystal symmetry is trigonal with space group P31c; sone crystals are hexagonal either because of partial disorder or twinning. The authors regard disorder as the more probable explanation.

One laboratory examined a sample prepared to represent a solid solution between $\mathrm{C}_{4} \mathrm{ASH}_{12}$ and $\mathrm{C}_{4} \mathrm{AH}_{13}$ with $\mathrm{SO}_{3}$ to $\mathrm{Al}_{2} \mathrm{O}_{3}$ as 0.75 to 1.00 . The constituents recognized were $\mathrm{C}_{4} \mathrm{~A} \overline{\mathrm{S}} \mathrm{H}_{12}, \mathrm{C}_{4} \mathrm{~A} \overline{\mathrm{S}} \mathrm{H}_{10}$, and $\mathrm{C}_{4} \mathrm{ACH}_{11}$ although the sample was examined in a chamber which had an atmosphere above 90 percent relative humidity.

Discussion :detection of C-S-H ge1

The results of examination of the hydrated silicates appear to show that $\mathrm{C}-\mathrm{S}-\mathrm{H}$ gel produced by the paste hydration of alite or $\beta-\mathrm{C}_{2} \mathrm{~S}$ for 5.3 years yields broad weak spacings at about 3.05 to $3.07 \mathrm{~A}$ and $1.82 \mathrm{~A}$, with the more intense at 3.05-3.07 A a symmetric, dropping steeply toward lower diffraction angles and tailing off gently to about 38 two-theta; the third spacing at 2.8 A reported for nearly amorphous calcium silicate hydrates by Taylor ${ }^{(18)}$ was not conspicuous in the hydrated alite (table 1.3, $F_{i} \cdot$ 7) examined in this program and was masked in the hydrated $3-C_{2} S$ by residual unhydrated materia1. The cement pastes of $0.65 \mathrm{w} / \mathrm{c}$ hydrated for 1 year (fig. 7) had the 2.80-A spacing masked in part by hydrogarnet and unhydrated silicates (cement No. 1), by residual unhydrated silicates (cement No. 2), and by residual silicates and aluminoferrites (cement No. 3). The pastes of $0.35 \mathrm{w} / \mathrm{c}$ at 365 days retained more unhydrated material and accordingly the 2.8 A spacing was not detected.

It appears to the writer that the results with respect to detection of C-S-H gel show the success of three approaches followed by participants. 
These are:

(1) Use of the Guinier camera.

(2) Use of a diffractometer with a wide detector slit (beam slit $3^{\circ}, 3^{\circ}$ beam slit as Soller, $0.2^{\circ}$ detector slit), at a scanning speed of $0.2^{\circ}$ per minute with logarithmic rate meter operation and full-scale chart deflection of 4000 counts per second. Radiation was nickel-filtered copper.

(3) Use of a diffractometer with an 0.006 in. receiving slit (about $0.08^{\circ}$ ) and a $1^{\circ}$ divergence slit (from 20 to 60 twotheta) or an $0.5^{\circ}$ divergence slit (from 8 to 20 two-theta) at a scanning speed of $0.125^{\circ}$ per minute with linear rate meter operation and full-scale chart deflection of 100 counts per second. Radiation was monochromated copper.

Both diffractometer techniques are suitable for use on samples producing broad peaks and both yield a small theoretical relative statistical deviation. (19)

Problems in identification of paste constituents

Several kinds of problems perplex the X-ray diffraction investigation of portland cement pastes. The diffraction pattern of unhydrated portland cement is in itself complex and many of the spacings are contributed to by more than one constituent. Many of these spacings of unhydrated cement persist in the hydrated pastes, particularly those of low water-cement ratio, although they diminish with the progress of hydration. A number of spacings of hydratior. products superpose upon spacings of unhydrated cement or upon spacings of other hydration products. 
An important constituent of pastes, C-S-H ge1, is almost amorphous and produces broad weak inconspicuous spacings. The platy hexagonal hydrated calcium aluminates with and without additional anionic groups have some spacings in common because they have similar crystal structures, and structural units in which $a_{0}$ is of the order of $5.73 \mathrm{~A} \pm 0.03$. They can be distinguished by measuring the longest spacing accurately but this is not simple. In the first place, these long spacings lie in the region of lower diffraction angles where errors in spacing due to errors in measurement of two-theta are maximized. (20) In the second place, a number of these substances are susceptible to carbonation and dehydration in ambient conditions found in laboratories that participated in this program, and that have led to many anomalies and disagreements in the literature. $(13,14,15,21,22)$.

The discussion in the preceding paragraph suggests that substantial improvements in the state of the art of examining zement pastes (and paste concentrates from concretes) require control of the temperature, relative humidity, and nature of the atmosphere in which the samples are prepared for $\mathrm{X}$-ray diffraction and in which the examination is conducted. Kantro, Copeland, and Anderson ${ }^{(10)}$ and Copeland, Kantro, and Verbeck (23) described procedures for achieving such control; Jones and Roberts (24) describe precautions taken in work with calcium aluminate hydrates which they noted were not always satisfactory in results. Seligmann and Greening ${ }^{(15)}$ discussed additional 
control measures; Dosch ${ }^{(25)}$ has described sophisticated apparatus; many diffractometers have been equipped with shopmade chambers that permit atmosphere control of some sort in laboratories where clays are examined. Even relatively simple control methods that permit maintaining a high humidity nitrogen atmosphere in a chamber surrounding the diffraction sample will greatly improve reproducibility in the examination of atmosphere-sensitive materials. However, the anomalies reported with respect to water content and basal spacing of many of the substances are still subject to disagreement. $(14,22)$

Identification of platy hexagonal hydrated calcium aluminate with and without additional anions. A considerable list of these substances can be made in which $a_{0}$ is about 5.73 and $c_{0}$ varies widely; $c_{0}$ varies with water content but $a_{0}$ apparently does not. $(22,26)$ Mixed crystals containing iron as well as aluminum can be formed in the $\mathrm{C}_{4}(A, F) \mathrm{H}_{\mathrm{X}}$ and $\mathrm{C}_{4}(A, F) \overline{\mathrm{S}} \mathrm{H}_{\mathrm{X}}$ groups at least and are not likely to be distinguished by $x$-ray diffraction from the unsubstituted forms. The ultimate products of cement hydration are believed to be substituted C-S-H ge1, low-sulfate calcium sulfoaluminoferrite hydrate, the lowest sulfate form of calcium sulfohydroxyaluninate hydrate, aluminosilicate hydrogarnet, and calcium hydroxide--except that in cements of relatively low $\mathrm{C}_{3} \mathrm{~A}$ content, ettringite and unhydrated calcium aluminoferrite solid solution may be present. (27) However, other products have been found in early hydration stages of mixtures simulating pastes. $(27,28)$ 
A list of the platy hexagonal hydrates which may be thought to exist in cenent pastes or mixtures like cement pastes is given below. Polytypes are not distinguished; $\mathrm{C}_{2} \mathrm{AH}_{3}, \mathrm{C}_{4} \mathrm{~A}\left(\mathrm{Cl}_{2}\right) \mathrm{H}_{10}$, and $\mathrm{C}_{2} \mathrm{ASH}_{8}$ (gehlenite hydrate) are omitted.

\author{
Second \\ Order \\ of Basal Low Order
}

\begin{tabular}{|c|c|c|c|c|c|c|}
\hline & Basal Spacing (0 & 001) & Spaci & & $(\mathrm{hK} \cdot$ & \\
\hline Composition & $\mathrm{d}, \mathrm{A}$ & $I$ & $d, A$ & $\bar{I}$ & $\mathrm{~d}, \mathrm{~A}$ & $I$ \\
\hline $\mathrm{C}_{4} \mathrm{AHI}_{19}$ & 10.6 & vos & 5.32 & $\mathrm{w}$ & 2.88 & s \\
\hline $\mathrm{C}_{4} \mathrm{All}_{13}$ & 7.92 & vvs & 3.95 & $\mathrm{~m}$ & 2.88 & $\mathrm{~s}, 2.86 \mathrm{vs}$ \\
\hline $\mathrm{C}_{4} \mathrm{~A} \overline{\mathrm{C}} \mathrm{H}_{11}$ & 7.60 & vvs & 3.80 & $\mathrm{~ms}$ & 2.36 & $\mathrm{~m}$ \\
\hline $\mathrm{C}_{4} \Lambda \overline{\mathrm{C}}_{0.5^{\mathrm{H}}} \mathrm{H}_{12}$ & 8.20 & vvs & 4.11 & $\mathrm{mw}$ & 2.88 & vs \\
\hline $\mathrm{C}_{4} \mathrm{~A} \overline{\mathrm{C}}_{0.5^{\mathrm{H}} 9-10}$ & 7.77 & vvs & 3.88 & $\mathrm{~s}$ & 2.38 & vs \\
\hline $\mathrm{C}_{4} \mathrm{~A}^{-} \mathrm{H}_{14-16}$ & 9.6 & & 4.80 & & $2.87 ?$ & vs \\
\hline $\mathrm{C}_{4} \Lambda \overline{\mathrm{S}} \mathrm{H}_{12}$ & 8.96 & vvs & 4.46 & s & 2.87 & vs \\
\hline $\mathrm{C}_{4} \mathrm{AS} \mathrm{AH}_{10}$ & 8.20 & vvs & 4.10 & $s$ & 2.87 & vs \\
\hline $\mathrm{C}_{4} \mathrm{~A} \overline{\mathbf{S}} \mathrm{H}_{3}$ & $28.0(3.05-7.35)$ & & N4.0 & & $?$ & \\
\hline
\end{tabular}

Host of these have a moderate to very strong spacing at $1.66 \mathrm{~A}$. As noted earlier, the long spacings fall in the range where errors in d due to errors in measuring two-theta are maximized. There are however means of increasing one's confidence that measurements in this region are adequately accurate. When ettringite is present and detectable, its spacings at 9.73 and $5.61 \mathrm{~A}$ are usually recognizable; if they are consistently read as $9.73 \pm 0.02$ and $5.61 \pm 0.02$ the spacings in between those two may be believed to be as read. If the sample being examined is a powder, it can be front-loaded and packed hard in the hope that 
preferred orientation of the platy hexagonal hydrates will be achieved and the second order of the basal spacing, which falls in a region in which spacings are less influenced by small errors in two-theta, will be accentuated. Some spacings and combinations are likely to remain ambiguous; these include the pair 7.92 and 7.77 (if it is possible to raise the humidity far enough 7.92 should go to $10.6 ; 7.77$ should go to 8.20 but no farther), the pair 7.77 and 7.60 (7.77 should go to 8.20 with increasing humidity but 7.60 should not change), and 8.20 (if it is $\mathrm{C}_{4} \mathrm{ASH}_{10}$ it will go to 8.96 but if it is $\mathrm{C}_{4} \mathrm{AC}_{0 .} \mathrm{H}_{12}$ it will not). Without the ability to control and change humidity around the sample it will be extremely difficult to establish the presence of $\mathrm{C}_{4} \mathrm{AH}_{13}$ as distinguished from $\mathrm{C}_{4} \mathrm{~A} \overline{\mathrm{C}}_{0 .} 5^{\mathrm{H}_{9}-10}$ (or $\mathrm{C}_{4} \mathrm{~A} \overline{\mathrm{S}} \mathrm{H}_{8}-$-which is not likely to form except in pastes dried at elevated temperature or over $\mathrm{P}_{2} \mathrm{O}_{5}{ }^{(25)}$ ) or to interpret a line at $8.2 \mathrm{~A}$.

Conclusion

X-ray diffractions permit the identification of many substances in cement paste. These include ettringite, calcium hydroxide, hydrogarnet, C-S-H ge1, tetracalcium aluminate carbonate11-hydrate, and substances in residual unhydrated cement such as calcium aluminoferrite solid solutions, $\mathrm{MgO}$, and residual silicates (but see (28)). If the humidity of the room is high enough or the atmosphere around the sample can be controlled, tetracalctum aluminate sulfate-12-hydrate can also be identified (or the sulfate-hydroxide solid solutions). Direct determination of 
$\mathrm{C}_{4} \mathrm{AH}_{13}$ if present in pastes requires control of humidity around the sample because it may easily be confused with other possible constituents.

A11 those who participated in this program are indebted for a valuable educational experience to Dr. George Kalousek who suggested and planned it, to those who prepared the pastes, and to Dr. Berman, Dr. Brunauer, and Dr. Greening who provided synthetic preparations and hydrated phases. 
1. E. P. Flint, H. F. McMurdie, and L. S. Wells, Formation of Hydrated Calcium Silicates at Elevated Temperatures and Pressures, Journal of Research of the National Bureau of Standards, Vol 21, pp 617-638, 1938.

2. H. F. W. Taylor, Hydrated Calcium Silicates, Part I, Journal of the Chemical Society, London, pp 3682-3690, 1950.

3. L. Heller and H. F. W. Taylor, ibid., Part II, pp 2397-2401, 1951; Part III, pp 1018-1020, 1952; Part IV, pp 2535-2541, 1952 .

4. H. F. W. Taylor, ibid., Part V, pp 163-171, 1953.

5. R. Turrizlani and G. Schippa, Investigation of the Quaternary Solids $\mathrm{CaO}-\mathrm{Al}_{2} \mathrm{O}_{3}-\mathrm{CaSO}_{4}-\mathrm{H}_{2} \mathrm{O}$ by X-Ray and DTA Methods, Ricerca Scientifica, Vol 24, pp 2356-2363, 1954 .

6. N. Fratini, G. Schippa, and R. Turriziani, ibid., Ann 25, p 57, 1955.

7. R. Turriziani and G. Schippa, Su11' Existenza del Monocarboalluninato di calcio idrato, Ricerca Scientifica, Ann 26, No. 9, pp 2792-2797, 1956.

8. G. L. Kalousek, Crystal Chemistry of Hydrous Calcium Silicates, Part I, pp 74-80, Journal of the American Ceramic Society, Vol 40, No. 3, pp 74-80, 1957.

9. H. G. Midgley quoted The Chemistry of Cement and Concrete by F. M. Lea and C. H. Desch, second edition, 1956, revised by F. M. Lea, Arnold, London, and St. Martin's Press, New York.

10. D. L. Kantro, I. E. Copeland, and E. R. Anderson, An X-Ray Diffraction Investigation of Hydrated Cement Pastes, Proc., Amerlcan Society for Testing and Materials, Vol 60, pp 1020-1035, 1960.

11. H. A. Berman, Preparation of a Carbonate-Free Complex Calcium Aluminate, Journal of Research of the NBS, A. Physics and Chemistry, Vol 69A, pp 45-51, 1965.

12. K. Mather, A. D. Buck, and W. I. Luke, Alka1i-Carbonate and A1kali-Silica Reactivity of Some Aggregates from South Dakota, Kansas, and Missouri, Highway Research Record No. 45, p 82, 1964. 
13. W. Dosch and H. zur Strassen, Untersuchung von Tetracalciumaluminat hydraten. I. Dieverschiedenen Hydratstufen und der Einfluss von Kohlensäure, Zement-Kalk-Gips, Vol 18, No. 5, pp 233-237, 1965.

14. W. Dosch, H. Keller, and H. zur Strassen, Discussion, pp 72-77, Vo1 II, Proc Fiith Int. Symposium on the Chemistry of Cement, Tokyo, $\overline{1968,1969 .}$

15. P. Jeligmann and N. R. Greening, New techniques for temperature and humidity control in X-ray diffractometry, Journal of PCA Research and Development Laboratories, Vol 4, No. 2, Pp 2-9, May 1962.

10. Joint Committee on Powder Diffraction Standards, Powder Diffraction File, set 9, 1959.

17. A. E. Moore and H. F. W. Taylor, Crystal structure of ettringite, Acta Crystallographica B26, pp 386-393.

18. H. F. W. Taylor, The Calcium Silicate Hydrates, p 183, 199, in The Chemistry of Cements, Vo1 1, ed. by H. F. W. Taylor, 1964.

19. H. P. Klug and L. E. Alexander, X-Ray Diffraction Procedures, $1954,305-317$.

20. International Union of Crystallography Commission on Crystallographic Data, Powder Data, Journal of Applied Crystallography, Vo1 4, pp 81-86, 1971.

21. F. E. Jones, Hydration of Calcium Aluminates and Ferrites, Fourth International Symposium on the Chemistry of Cement, Washington, D. C., 1960, Vo1 1, pp 205-242, with discussion pp $242-246,1962$.

22. H. E. Schwiete and U. Ludwig, Crystal structures and properties of cement hydration products (hydrated calcium aluminates and ferrites, Proc Fifth International Symposium on the Chemistry of Cement, Tokyo, 1968, 1969, pp 37-67; discussion by M. H. Roberts, W. Dosch et a1, A. E. Moore and H. F. W. Taylor; supplementary papers by M. H. Roberts, pp 104-117; S. J. Ahmed, L. S. D. Glasser, and H. F. W. Taylor, pp 118-126.

23. L. E. Copeland, D. L. Kantro, and G. Verbeck, Chemistry of Hydration of Portland Cement, Proc Fourth International Symposium, Washington, D. C., 1960, Vol 1, pp 429-465, 1962.

24. F. E. Jones and $\mathrm{M}$. H. Roberts, The System $\mathrm{CaO}-\mathrm{Al}_{2} \mathrm{O}_{3}-\mathrm{H}_{2} \mathrm{O}$ at $25^{\circ} \mathrm{C}$, Building Research Current Papers, Research Series 1, Bullding Research Station, 1962.

25. W. Dosch, Röntgen-feinstrukturuntersuchung luftemp Findlicher pulverpräparate, Zement-Ka1k-Gips, Vo1 18, No. 5, 1965, pp 226-232. 
26. H. F. W. Taylor, The Chemistry of Cements, Vol 2, pp 386-400.

27. P. Seligmann and N. R. Greening, Phase equilibria of cementwater, Proc Fifth International Symposium on the Chemistry of Cement, Tokyo, 1968, Vo1 2, pp 179-200.

28. L. E. Copeland and D. L. Kantro, Hydration of portland cement, Proc Fifth International Symposium on the Chemistry of Cement, Tokyo, 1968, 1969, pp 387-420. 
Table 1

\section{Samples}

Cement Pastes

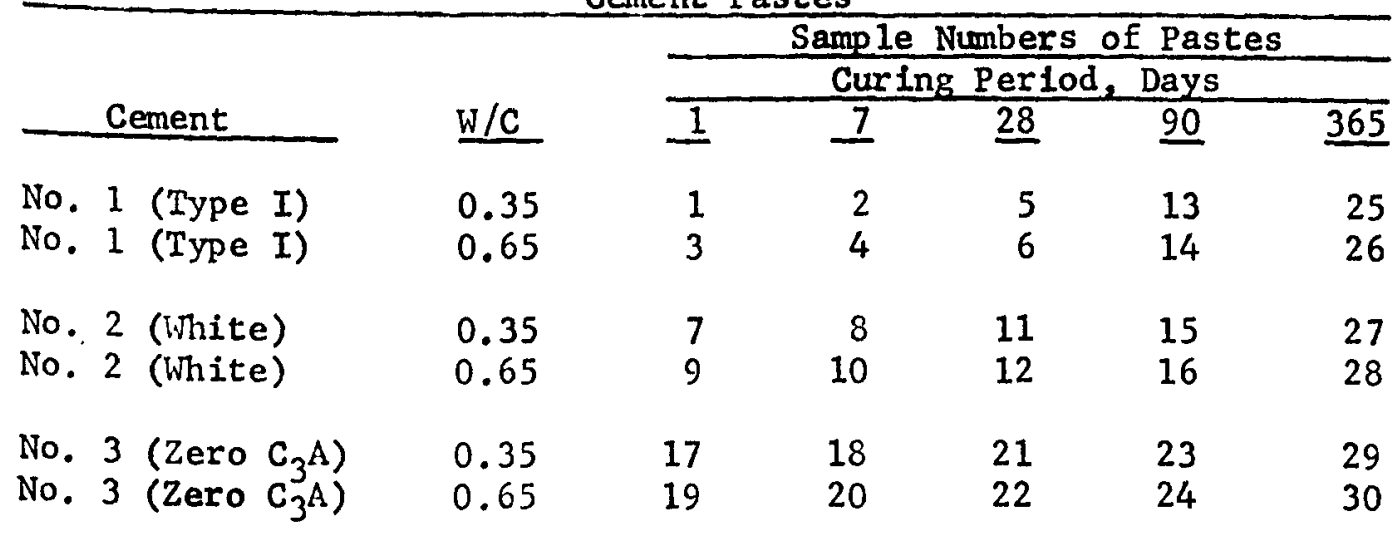

Laboratories 1 through 4 , and 6 , examined all 30 samples. Laboratory 5 examined samples 7 through 30 .

hydrated Phases and Compounds

Sample No. Description

Source

35

Hydrated alite Hydrated 5.3 years

PCA

36

Hydrated $B-C_{2} S$ Hydrated 5.3 years

PCA

37

Tetracalcium a luminate hemicarbonate-12-hydrate

PCA

38

Tetracalcium aluminate carbonate-11-hydrate

PCA

39

Tetracalcium aluminate monosulfate-12-hydrate

NBS

40 Tetracalcium aluminate-10.5-hydrate

PCA

41

Ettringite

NBS

Ettringite

PCA 


\section{Table 2}

Hydrated Phases Examined by Six Laboratories

Sample No.

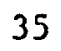

36

37

38

39

40

41

\section{Hydrated alite*}

Hydrated $B-\mathrm{C}_{2} \mathrm{~S} *$

Tricalcium hemicarboaluminate*

Tricalcium monocarboaluminate* Calcium monosul foaluminate**

$\mathrm{C}_{4} \mathrm{AH}_{10.5^{*}}$

Ettringite**

Monosulfate $\left(0.75 \mathrm{SO}_{3} / \mathrm{Al}_{2} \mathrm{O}_{3}\right)^{*}$

Ettringite*
Laboratory Number

$\underline{1} \quad \underline{2} \quad \underline{3} \quad \underline{4} \quad \underline{5} \quad \underline{6}$

$x \quad x \quad x \quad x$

$\begin{array}{llllll}x & x & x & - & x & x\end{array}$

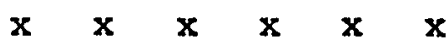

$\begin{array}{llllll}x & x & x & x & x & x\end{array}$

$\begin{array}{llllllllll} & x & x & x & x & - & x\end{array}$

$\begin{array}{llllll} & x & x & - & x & x\end{array}$

$\mathrm{x} \quad \mathrm{x} \quad \mathrm{x}-\mathrm{x} \quad \mathrm{x}$

$-\quad-\quad x-\overline{-}-$

* Prepared by the Portland Cement Association Research and Development Laboratories.

to* Prepared by the National Bureau of Standards. 


\section{Table 3}

\section{Instrumentation}

Laboratory

\begin{tabular}{|c|c|c|c|c|c|c|}
\hline 1 & 2 & 3 & 4 & 5 & 6 & $7 *$ \\
\hline - & $\mathbf{x}$ & $x$ & - & - & - & \\
\hline $\mathbf{x}$ & - & - & $x$ & - & - & $x$ \\
\hline - & - & - & - & $x$ & - & \\
\hline
\end{tabular}

\section{Guinier Camera}

Monochromat or

Radiation

$\mathrm{Cu}$

$\mathrm{Cu}$

$\mathrm{Cu}$

Cu

$\mathrm{Cu} \quad \mathrm{CuK \alpha} \quad \mathrm{CuK} \alpha$

Filter

Nickel Nickel Nickel Nickel Nicke1 - $0.0007 \quad 0.0007$ in. in.

Detector

Film

Proportional Counter Scintillation Counter Geiger Counter

$\begin{array}{llll}- & - & - & - \\ x & - & x & - \\ - & - & - & -\end{array}$

$\begin{array}{lll}- & x & - \\ - & - & - \\ - & - & - \\ - & - & -\end{array}$

* One examination made using a high-intensity X-ray tube, nickel filter, pulse height analysis, and a proportional counter as a detector.

** Curved crysta1 monochromator with fine focus $X$-ray tube and geiger counter detector. 
Table $4 a$

Operating Conditions for Examination of Cement Pastes

Laboratory 1

KV of X-ray tube ma of $X$-ray tube

Apparent watts (b)

Detector

Scanning speed, deg/min

S1its

Chart full scale deflection Time constant

Pulse height selection

$$
35
$$

15

525

Proportional counter

0.25

Divergence: $1 \mathrm{deg}$ Scatter: 1 deg Receiving 0.003 in.0.03

Linear, $240 \mathrm{c} / \mathrm{s}$ $4 \mathrm{sec}$

Scale factor 8 Multiplier 0.6

No
Laboratory 2

50

16

800

Proportional counter

2

Beam 1 deg Medium Resolution Soller Medium Resolution

Detector:0.2 deg

Linear, $200 \mathrm{c} / \mathrm{s}$ $3 \mathrm{sec}$

$-$

$-$

No
Laboratory 3

$\begin{array}{lr}50(a) & 50(a) \\ 16^{(a)} & 21^{(a)} \\ 800^{(a)} & 1050^{(a)}\end{array}$

Proportional counter

$\begin{array}{lll} & 0.2 & \\ \frac{7-202 \theta}{1 \mathrm{deg}} & & \frac{20-602 \theta}{3 \mathrm{deg}} \\ 3 \mathrm{deg} & & 3 \mathrm{deg} \\ 0.2 \mathrm{deg} & & 0.2 \mathrm{deg}\end{array}$

Logarithmic, $4000 \mathrm{c} / \mathrm{s}$ (c) $30 \mathrm{sec} / 7.5 \mathrm{sec} / 2 \mathrm{sec}(d)$

Not applicable Not applicable

Yes

(a) Two diffractometers used; the one at $50 \mathrm{KVCP}$ and 21 ma operated at constant potential.

(b) $(\mathrm{KV} \times(\mathrm{ma})=$ apparent watts.

(c) All pastes of $0.65 \mathrm{w} / \mathrm{c}$ were re-examined in the range 7-21 $2 \theta$ using a linear scale of $1000 \mathrm{c} / \mathrm{s}$, with time constant $=8 \mathrm{sec}$, except that the $\mathrm{Ca}(\mathrm{OH})_{2}$ peak at 18 2- $\theta$ was also scamed with tc $=4$ sec ( samples $3,4,6,14,26 ; 9,16 ; 22,30)$ or with tc $=2$ sec $(\operatorname{samples} 26,9,10,12,16,19)$. During this examination, the intensities of all peaks were scaled.

(d) In the first, second, and third decades, respectively, of the logarithmic range. 
Table 4b

Qperating Conditions for Examination of Cement Pastes

Laboratory 4

$K V$ of $x-z a y$ tube ma of X-ray tube

Apparent watts

Detector

Slits: Divergence

Scatter

Recelving

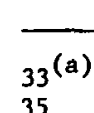

40 (b)

35

1155

1200

Scintillation counter

$1 \mathrm{deg}$

$1 \mathrm{deg}$

1 deg

1 deg

$0.006 \mathrm{in.}$
Scanning speed

$40^{(c)}$

35

1400

$0.25 \mathrm{deg} / \mathrm{min} \quad 0.5 \mathrm{deg} / \mathrm{min} \quad 0.5 \mathrm{deg} / \mathrm{min}$

0.006 in.

$1 \mathrm{deg}$

1 deg

0.006 in.

$-0.006 \mathrm{deg}$

Chart full scale deflection

Time constant

$500 \mathrm{c} / \mathrm{s}$

$500 \mathrm{c} / \mathrm{s}$

$1000 \mathrm{c} / \mathrm{s}$

4

yes

Pulse helght selection
Laboratory 5

Laboratory 7

$\begin{array}{ll}40 & 40 \\ 18 & 35\end{array}$

720

\section{15}

525

\section{0}

1400
Scintillation counter

$$
0.5 \mathrm{deg} / \mathrm{min}
$$

\section{$1 \mathrm{deg}$ \\ 1 deg}

$0.2 \mathrm{~mm}$

\begin{abstract}
$400 \mathrm{c} / \mathrm{s}^{(\mathrm{d})}$
\end{abstract}
no

4

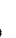

\begin{abstract}
$800 \mathrm{c} / \mathrm{s}^{(e)}$
\end{abstract}
2

yes

\section{2}

yes (a) $33 \mathrm{kVp} \times 35$ ma samples 1 through 16

(b) $40 \mathrm{KVp} \times 30$ ma samples 17 through 24

(c) $40 \mathrm{kVp} \times 35$ ma samples 25 through 30

(d) Samples 7 through 20; scale factor 8 , multiplier 1

(e) Samples 21 through 24 ;

(g) From 60 to $202 \theta, 1 \mathrm{deg}$ divergence and scatter slits; from 20 to $52 \theta, 0.5$ divergence and scatter slits

(h) Pastes from 60 to $202 \theta$

(i) Cements 60 to 2020
Monochromator with Proportional counter Geiger counter

$0.125 \mathrm{deg} / \mathrm{min}$

$0.125 \mathrm{deg} / \mathrm{min}$

\section{$1 \mathrm{deg}(\mathrm{g})$}

$1 \mathrm{deg}$

0.006 in. $\simeq 0.06 \mathrm{deg} 0.006 \mathrm{in}$.

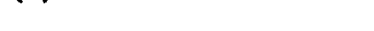


Strong Lines and Interferences in Port land Cement Pastes

\section{d, $\mathrm{m} \times 10^{-10}$}

$9.73^{(1)}$ Ettringite $I=100 ; 9.6 \mathrm{~A} \quad \mathrm{C}_{4} \mathrm{As}^{\mathrm{S}} \mathrm{H}_{14-15}(2)$

$9.0 \quad \mathrm{C}_{4} \mathrm{As}_{\mathrm{S}} \mathrm{H}_{12}(0001)^{(3)}$

$8.2 \quad \mathrm{C}_{4} \mathrm{ASH} 10, \mathrm{C}_{4} \mathrm{~A}_{0.5^{\mathrm{H}}}{ }^{(4)}$ (0001) of both

$7.95 \quad \mathrm{C}_{4} \mathrm{AH}_{13}(6) \quad(0001)$

$7.77 \quad \mathrm{C}_{4} \mathrm{~A} \overline{\mathrm{C}}_{0.5^{\mathrm{H}_{9}}}{ }^{(4)}(0001)$

$7.62 \cdot \mathrm{C}_{4} \mathrm{ACH}_{10-11}{ }^{(4)}$ (0001)

7.2-7.4 Aluminoferrite solid solutions ${ }^{(7)} ; 7.2$ of $\mathrm{C}_{4} \mathrm{~A} \overline{\mathrm{C}} \mathrm{H}_{6}{ }^{(4)}$

$5.94 \quad$ Alite ${ }^{(7)}$

5.61 Ettringite, $I=31$

$5.06 \quad$ Hydrogarnet ${ }^{(8)}, I=95$

$4.90 \quad \mathrm{CH}^{(1)} ; \mathrm{C}_{4} \Lambda \overline{\mathrm{s}} \mathrm{H}_{12}$ weak

4.69 Ettringite, $I=36$

$4.62 \quad \mathrm{C}_{4} \mathrm{AC} \widetilde{C}_{0.5^{H}} \mathrm{H}_{12}$

$4.48 \quad \mathrm{C}_{4} \mathrm{~A} \overline{\mathrm{S}} \mathrm{H}_{12} ; \mathrm{C}_{4} \mathrm{AH}_{13}$ weak

4.38 Hydrogarnet, weal but not subject to interference.

$4.10 \quad \mathrm{C}_{4} \mathrm{~A} \overline{\mathrm{C}}_{0 .} 5^{\mathrm{H}_{12}} ; \mathrm{C}_{4} \mathrm{~A} \overline{\mathrm{S}} \mathrm{H}_{10} \quad(0002)$

$4.00 \quad \mathrm{C}_{4} \mathrm{AS} \mathrm{S}_{12}$

$3.95 \quad \mathrm{C}_{4} \mathrm{AH}_{13} \quad(0002)$

3.88 Ettringite; $\mathrm{C}_{4} \mathrm{AC}_{0 .} 5^{\mathrm{H}} 10 \quad(0002) ; \mathrm{C}_{4} \overline{A C}_{0.5} \mathrm{H}_{12} ; \mathrm{C}_{4} \mathrm{AH}_{13}$ weak; Alite; Calcite weak.

$3.78 \quad \mathrm{C}_{4} \mathrm{AC}_{11} \quad(0002)$

$3.66 \mathrm{C}_{4} \mathrm{AS} \mathrm{H}_{12}$; aluminoferrite solid solution $3.63-3.70$

$3.62 \mathrm{C}_{4} \mathrm{AH}_{13}$ weak

3.48 Ettringite, probably not detected. 


\section{Table 5 (Continued)}

$\mathrm{d}, \mathrm{m} \times 10^{-10}$

3.30 Hydrogarnet, weak but not interfered with in paste

$3.112 \mathrm{CH}$, ordinarily masks 3.10 of Hydrogarnet

$3.06 \quad \mathrm{C}-\mathrm{S}-\mathrm{H}^{(9)}$

3.04 Alite, Belite, 3.035 of calcite ${ }^{(1)}$

2.97 Alite

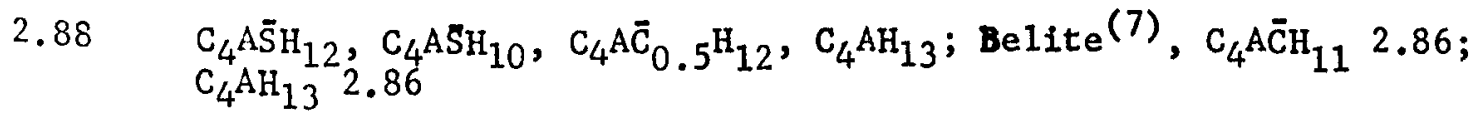

$2.80 \quad \mathrm{C}-\mathrm{S}-\mathrm{H}$

2.77 Alite and Belite, Hydrogarnet, Ettringite

2.75-2.74 Alite and Belite; $\mathrm{C}_{4} \mathrm{~A} \overline{\mathrm{S}} \mathrm{H}_{12} 2.72$

$2.70 \quad \mathrm{C}_{3} \mathrm{~A} ; 2.69$ of $\mathrm{C}_{4} \mathrm{AH}_{13}$

2.63-2.68 Aluminoferrite solid solutions

$2.628 \quad \mathrm{CH} \quad \mathrm{I}=100$

2.564 Ettringite

2.54 Belite, $\mathrm{C}_{4} \mathrm{AC}_{0 .} \overline{\mathrm{H}}_{12}, 2.53$ of Hydrogarnet; $2.524 \mathrm{C}_{4} \mathrm{~A} \bar{C}_{11}$ (7)

2.495 Calcite, $\mathrm{C}_{4} \mathrm{AH}_{13}, \mathrm{C}_{4} \mathrm{AC}_{11}$

$2.47 \quad \mathrm{C}_{4} \mathrm{AH}_{13}$

$2.45 \quad \mathrm{C}_{4} \mathrm{AH}_{13}, \mathrm{C}_{4} \mathrm{~A} \overline{S H}_{12}, \mathrm{C}_{4} \mathrm{AC}_{0 .} \mathrm{H}_{12}$

$2.42 \mathrm{C}_{4} \mathrm{~A} \overline{\mathrm{S}} \mathrm{H}_{12}, \mathrm{C}_{4} \mathrm{~A} \overline{\mathrm{C}} \mathrm{H}_{11}$

2.40 CaO - improbable in paste

$2.35 \quad \mathrm{C}_{4} \mathrm{~A}_{0 .} \overline{\mathrm{H}}_{12}, 2.34$ of $\mathrm{C}_{4} \mathrm{~A} \overline{\mathrm{CH}}_{11}$

2.285 Calcite - weak

2.27 Hydrogarnet, $I=100 ; 2.26$ of $\mathrm{C}_{4} \mathrm{~A}^{\bar{S} H_{12}}$

2.23 Ettringite, $\mathrm{C}_{4} \mathrm{~A} \overline{\mathrm{C}}_{0 .}{ }^{\mathrm{H}_{12}}$ 


\section{Table 5 (Continued)}

$\underline{\mathrm{d}, \mathrm{m} \times 10^{-10}}$

2.209 Ettringite

2.185 Alite, Belite

2.169 Alite, Belite

2.10 Mg0 I $=100 ; 2.095$ Calcite; 2.09 weak Alite, Belite

$2.07 \quad \mathrm{C}_{4} \mathrm{ASS}_{12}$

2.00 Hydrogarnet $I=95$

$1.927 \mathrm{CH}$

$1.796 \quad \mathrm{CH}$

$1.687 \mathrm{CH}$

$1.66 \mathrm{C}_{4} \mathrm{~A} \overline{\mathrm{S}} \mathrm{H}_{12}, \mathrm{C}_{4} \mathrm{~A} \overline{\mathrm{C}}_{0.5} \mathrm{H}_{12}, \mathrm{C}_{4} \mathrm{~A} \overline{\mathrm{C}} \mathrm{H}_{11}, \mathrm{C}_{4} \mathrm{AH}_{13}$ 
(1) Ettringite, H. E. Swanson, N. T. Gilfrich, M. I. Cook, R. Stinchfield, and P. C. Parks, Standard X-Ray Diffraction Powder Patterns, Vo1 8, NBS Circular 539, p 3, 1959.

Calcium hydroxide, H. E. Swanson and E. Tatge, ibid, Vol 1, 1953, p 59; Mg0, p 37, Ca0, p 43, Calcite, H. E. Swanson and R. Fuyat, ibid, Vol 2, 1953, p 51 .

(2) P. Seligmann and N. R. Greening, Studies of Early Hydration Reactions of Portland Cement by X-Ray Diffraction, Highway Research Record No. 62 , pp 80-105, 1964.

(3) $\mathrm{C}_{4} \mathrm{~A} \bar{S}_{12}$, this program and H. F. W. Taylor, ed., The Chemistry of Cements, Vo1 2, p 396, 1964.

(4) H. E. Schwiete and Udo Ludwig, Crystal Structures and Properties of Cement Hydration Products, Proc., Fifth Int. Sym. on Chem. of Cement, Tokyo, 1968, Vo1 II, pp 37-67, 1969;

(5) ibid, and this program;

(6) M. H. Roberts, Calcium aluminate hydrates and related basic salt solid solutions, ibid, pp 104-117.

(7) H. F. W. Taylor, The Chemistry of Cements, Vo1 2, pp 347-404, 1964.

(8) Spacings from D. L. Kantro et al, An X-Ray diffraction investigation of hydrated portland cement pastes, Am Soc Testing Mats, Proc., Vo1 60, pp 1020-1035, 1960. Intensities calculated from fig. in B. Marchese and $R$. Sersale, Stability of hydrogarnet series terms to sulphate attack, Proc., Fifth Int Sym on the Chemistry of Cement, Tokyo, 1968, Vo1 II, pp 133-137.

(9) Data from this program. 
Table 6

Cement No. 1: Constituents of Pastes with $\mathrm{W} / \mathrm{C}=0.35$

\begin{tabular}{|c|c|c|c|c|c|}
\hline & \multicolumn{5}{|c|}{ Curing, Days } \\
\hline & $\underline{1}$ & 7 & 28 & 90 & 365 \\
\hline Ettŕingite & $\mathbf{x}$ & $\mathbf{x}$ & $\mathbf{x}$ & $\mathbf{x}$ & $\mathbf{x}$ \\
\hline $\mathrm{C}_{4} \mathrm{ASH} \mathrm{H}_{12}$ & - & $\mathbf{x}$ & $\mathbf{x}$ & $\mathbf{x}$ & $\mathrm{x}$ \\
\hline Calcium hydroxide & $\mathbf{x}$ & $\mathrm{x}$ & $\mathbf{x}$ & $\mathbf{x}$ & $\mathbf{x}$ \\
\hline Hydrogarnet & - & tr? & $\operatorname{tr} ?$ & $\mathbf{x}$ & $\mathbf{x}$ \\
\hline $\mathrm{C}_{4} \mathrm{~A} \overline{\mathrm{C}} \mathrm{H}_{11}$ & - & - & - & $\mathbf{x}$ & tr \\
\hline $\mathrm{C}_{4} \mathrm{AH}_{\mathrm{X}}$ & - & $\mathbf{x}$ & $\mathbf{x}$ & $x$ & - \\
\hline $\mathrm{C}_{3} \mathrm{AH}_{6}$ & - & - & - & $?$ & - \\
\hline$C-S-H$ & $\mathbf{x}$ & $\mathbf{x}$ & $\mathbf{x}$ & $\mathbf{x}$ & $\mathbf{x}$ \\
\hline Alite & $\mathbf{x}$ & $\mathbf{x}$ & $\mathbf{x}$ & $\mathrm{x}$ & $\mathbf{x}$ \\
\hline Belite & $\mathbf{x}$ & $\mathbf{x}$ & $\mathbf{x}$ & $\mathbf{x}$ & $\mathbf{x}$ \\
\hline$C_{3} A$ & $\mathrm{x}$ & $x$ & $\mathbf{x}$ & $\mathbf{x}$ & $x$ \\
\hline Aluminoferrite & $\mathbf{x}$ & $x$ & $\mathbf{x}$ & $\mathbf{x}$ & $\mathbf{x}$ \\
\hline $\mathrm{MgO}$ & $\mathbf{x}$ & $x$ & $\mathbf{x}$ & $x$ & $\mathrm{x}$ \\
\hline
\end{tabular}

NOTES: $t r=$ trace; $t r ?=$ possible trace.

Laboratories Reporting Each Constituent

\begin{tabular}{|c|c|c|c|c|}
\hline Ettringite & 6 & 6 & 5 & 5 \\
\hline $\mathrm{C}_{4} \mathrm{AS} \mathrm{SH}_{12}$ & - & 4 & 4 & 6 \\
\hline Calcium hydroxide & 7 & 7 & 7 & 7 \\
\hline Hydrogarnet & - & 1 & 1 & 1 \\
\hline $\mathrm{C}_{4} \mathrm{~A} \overline{\mathrm{C}} \mathrm{H}_{11}$ & - & - & - & 1 \\
\hline $\mathrm{C}_{4} \mathrm{AH}_{\mathrm{x}} \quad($ Total of 2$)$ & - & 1 & 1 & 1 \\
\hline $\mathrm{C}_{3} \mathrm{AH}_{6}$ & - & $\overline{2}$ & $\overline{-}$ & $\frac{1}{c}$ \\
\hline $\mathrm{C}-\mathrm{S}-\mathrm{H}$ & 1 & 2 & 4 & 5 \\
\hline Alite & 4 & 4 & 4 & 5 \\
\hline Belite & 4 & 4 & 4 & 5 \\
\hline $\mathrm{C}_{3} \mathrm{~A}$ & 5 & 4 & 4 & 4 \\
\hline Aluminoferrite & 4 & 4 & 4 & 4 \\
\hline $\mathrm{MgO}$ & 4 & 4 & 4 & 5 \\
\hline
\end{tabular}


Table 7

Cement No. 2: Constituents of Pastes with W/C $=0.35$

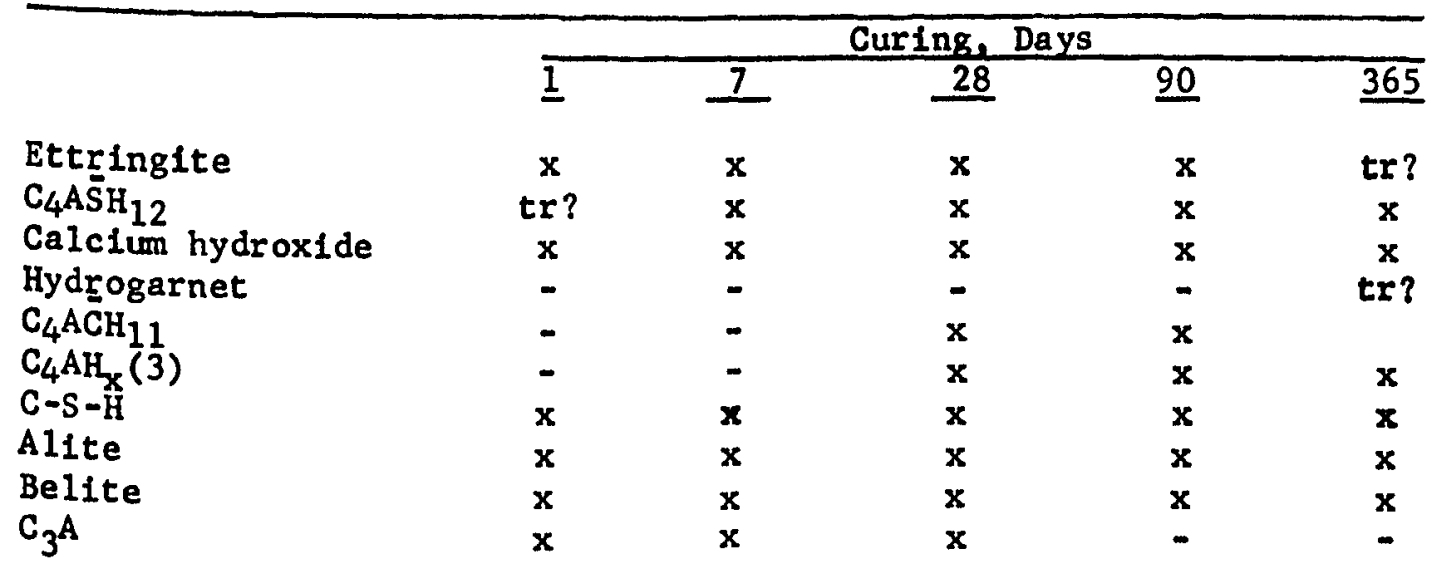

NOTE: tr? = possible trace.

Laboratories Reporting Each Constituent

Ettringite

$\mathrm{C}_{4} \mathrm{ASH}_{12}$

Calcium hydroxide

Hydrogarnet

$\mathrm{C}_{4} \mathrm{~A} \overline{C H}_{11}$

$\mathrm{C}_{4} \mathrm{AH}_{\mathrm{X}}$

C-S $-\mathrm{h}$

Alite

Belite

$\mathrm{C}_{3} \mathrm{~A}$

$\begin{array}{ll}5 & 5 \\ 2 & 4 \\ 7 & 7 \\ - & - \\ - & - \\ - & 5 \\ 1 & 2 \\ 5 & 5 \\ 5 & 5 \\ 5 & 2\end{array}$

$\begin{array}{lll}5 & 4 & 1 \\ 5 & 5 & 2 \\ 7 & 7 & 6 \\ -7 & - & 1 \\ 2 & 1 & - \\ 1 & 1 & 1 \\ 4 & 5 & 4 \\ 5 & 5 & 3 \\ 5 & 4 & 3 \\ 2 & - & -\end{array}$


Cement No. 3: Constituents of Pastes with $\mathrm{W} / \mathrm{C}=0.35$

\begin{tabular}{|c|c|c|c|c|c|}
\hline & \multicolumn{5}{|c|}{ Curing, Days } \\
\hline & 1 & 7 & 28 & 90 & 365 \\
\hline Ettringite & $\mathbf{x}$ & $\mathbf{x}$ & $\mathbf{x}$ & $\mathbf{x}$ & $\operatorname{tr}$ \\
\hline $\mathrm{C}_{4} \mathrm{~A} \overline{\mathrm{S}} \mathrm{H}_{12}$ & $\operatorname{tr} ?$ & $\operatorname{tr}$ & $\operatorname{tr}$ & tr & tr? \\
\hline Calcium hydroxide & $\mathbf{x}$ & $\mathbf{x}$ & $\mathbf{x}$ & $\mathbf{x}$ & $\mathrm{x}$ \\
\hline $\mathrm{C}_{4} \mathrm{AH}_{\mathrm{x}}$ & tr & - & - & - & - \\
\hline $\mathrm{C}-\mathrm{S}-\mathrm{H}$ & $\mathbf{x}$ & $\mathbf{x}$ & $\mathbf{x}$ & $\mathbf{x}$ & $\mathbf{x}$ \\
\hline Alite & $\mathrm{x}$ & $\mathbf{x}$ & $\mathbf{x}$ & $\mathbf{x}$ & $\mathbf{x}$ \\
\hline Belite & $\mathrm{x}$ & $\mathbf{x}$ & $\mathbf{x}$ & $\mathbf{x}$ & $x$ \\
\hline Aluminoferrite & $\mathrm{x}$ & $\mathrm{x}$ & $\mathrm{x}$ & $x$ & $x$ \\
\hline
\end{tabular}

NOTES: tr = trace; tr? = possible trace.

Iaboratories Reporting Each Constituent

Ettringite

$\mathrm{C}_{4} \mathrm{~A} \overline{\mathrm{S}} \mathrm{H}_{12}$

Calcium hydroxide

$\mathrm{C}_{4} \mathrm{AH}_{\mathrm{x}}$ C-S $-\mathrm{H}$

Alite

Belite

Aluminoferrite

$\begin{array}{ll}4 & 3 \\ 1 & 2 \\ 7 & 7 \\ 1 & - \\ 1 & 4 \\ 5 & 5 \\ 5 & 4 \\ 6 & 6\end{array}$

4
2
7
-
4
5
4
6

5

2

7

$-$

5

5

3

6

2
1
6
-
3
5
2
6


Table 9

Cement No. 1: Constituents of Pastes of W/C $=0.65$

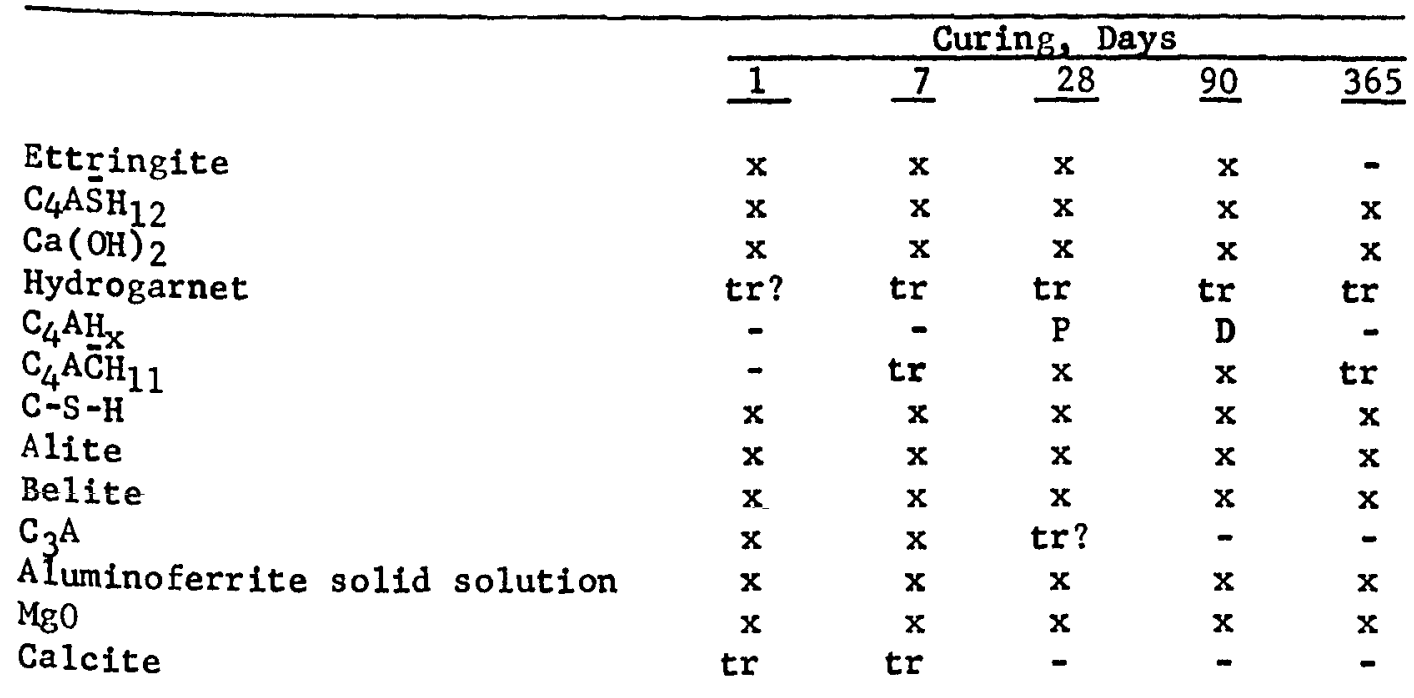

NOTES: $t r$ ? $=$ possible trace; $P=$ possible; $D=$ doubtful.

Laboratories Reporting Each Constituent

Ettringite

$\mathrm{C}_{4} \mathrm{~A} \overline{\mathrm{S}} \mathrm{H}_{12}$

$\mathrm{Ca}(\mathrm{OH})_{2}$

Hydrogarnet

$\mathrm{C}_{4} \mathrm{AH}_{\mathrm{X}}$

$\mathrm{C}_{4} \mathrm{ACH}_{11}$

$\mathrm{C}-\mathrm{S}-\mathrm{H}$

Alite

Belite

$\mathrm{C}_{3} \mathrm{~A}$

Aluminoferrite solid solution $\mathrm{MgO}$

Calcite
6

1

7

1

$-$

3

11

4

4

5

4

4

1

\section{4}

6

7

2

$-$

3

1

4

4

3

4

4

1

$\begin{array}{lll}4 & 4 & - \\ 5 & 6 & 5 \\ 7 & 7 & 6 \\ 2 & 2 & 2 \\ 1 & 1 & - \\ 3 & 4 & 1 \\ 4 & 4 & 2 \\ 4 & 5 & 1 \\ 4 & 4 & 2 \\ 1 & - & - \\ 4 & 4 & 1 \\ 4 & 5 & 2 \\ - & - & -\end{array}$


Cement No. 2: Constituents of Pastes of $\mathrm{W} / \mathrm{C}=0.65$

\begin{tabular}{|c|c|c|c|c|c|}
\hline & \multicolumn{5}{|c|}{ Curing, Days } \\
\hline & 1 & 7 & 28 & 90 & 365 \\
\hline Ettringite & $x$ & $x$ & $\mathbf{x}$ & $\mathbf{x}$ & $\mathbf{x}$ \\
\hline $\mathrm{C}_{4} \mathrm{ASH}_{12}$ & - & $\mathbf{x}$ & $\mathbf{x}$ & $\mathbf{x}$ & $\mathbf{x}$ \\
\hline $\mathrm{Ca}(\mathrm{OH})_{2}$ & $\mathbf{x}$ & $\mathbf{x}$ & $\mathbf{x}$ & $x$ & $\mathbf{x}$ \\
\hline $\mathrm{C}_{4} \mathrm{AH}_{-\mathrm{x}}$ & - & - & - & - & $\mathbf{x}$ \\
\hline $\mathrm{C}_{4} \mathrm{AC} \hat{\mathrm{CH}}_{11}$ & $\mathbf{x}$ & $\mathbf{x}$ & $\mathbf{x}$ & $\mathbf{x}$ & $\operatorname{tr}$ \\
\hline $\mathrm{C}-\mathrm{S}-\mathrm{H}^{2}$ & $\mathbf{x}$ & $\mathbf{x}$ & $\mathbf{x}$ & $x$ & $\mathbf{x}$ \\
\hline Alite & $\mathbf{x}$ & $\mathbf{x}$ & $\mathbf{x}$ & $\mathbf{x}$ & $\mathbf{x}$ \\
\hline Belite & $\mathbf{x}$ & $\mathbf{x}$ & $\mathbf{x}$ & $\mathbf{x}$ & $\mathbf{x}$ \\
\hline $\mathrm{C}_{3} \mathrm{~A}$ & $\mathbf{x}$ & $\mathbf{x}$ & $\mathbf{x}$ & $\mathbf{x}$ & - \\
\hline Calcite & tr? & - & - & - & - \\
\hline
\end{tabular}

NOTES: $\operatorname{tr}=$ trace; $t r$ ? = possible trace.

Laboratories Reporting Each Constituent

\begin{tabular}{|c|c|c|c|c|c|}
\hline Ettringite & 6 & 5 & 5 & 4 & 4 \\
\hline $\mathrm{C}_{4} \mathrm{AS} \mathrm{H}_{12}$ & - & 7 & 7 & 6 & 5 \\
\hline $\mathrm{Ca}(\mathrm{OH})_{2}$ & 7 & 7 & 7 & 7 & 6 \\
\hline $\mathrm{C}_{4} \mathrm{AH}_{\mathrm{x}}$ & - & - & - & - & 1 \\
\hline $\mathrm{C}_{4} \mathrm{~A} \overline{\mathrm{CH}} \mathrm{H} 1 \mathrm{~T}$ (Tota 1 of 3 ) & 1 & 2 & 2 & 2 & 1 \\
\hline $\mathrm{C}-\mathrm{S}-\mathrm{H}$ & 1 & 3 & 4 & 4 & 3 \\
\hline Álite & 5 & 5 & 5 & 5 & 1 \\
\hline Belite & 5 & 5 & 5 & 4 & 2 \\
\hline $\mathrm{C}_{3} \mathrm{~A}$ & 5 & 2 & 2 & 1 & - \\
\hline Calcite & 1 & - & - & - & - \\
\hline
\end{tabular}


Table 11

Cement No. 3: Constituents of Pastes of W/C $=0.65$

\begin{tabular}{|c|c|c|c|c|c|}
\hline & & & $\mathrm{lng}_{2}$ & & \\
\hline & 1 & 7 & 28 & 90 & 365 \\
\hline Ettringite & $\mathbf{x}$ & $\mathbf{x}$ & $\mathbf{x}$ & $\mathbf{x}$ & $x$ \\
\hline $\mathrm{C}_{4} \mathrm{AS} \mathrm{H}_{12}$ & - & $\operatorname{tr}$ & $\operatorname{tr} ?$ & tr & $?$ \\
\hline $\mathrm{Ca}(\mathrm{OH})_{2}$ & $x$ & $x$ & $\mathbf{x}$ & $\mathbf{x}$ & $\mathbf{x}$ \\
\hline $\mathrm{C}_{4} \mathrm{AH}_{\mathrm{x}}$ & - & tr & - & tr & - \\
\hline $\mathrm{C}_{4} \mathrm{ACH}_{11}$ & - & - & - & - & $\operatorname{tr} ?$ \\
\hline $\mathrm{C}^{4}-\mathrm{S}-\mathrm{H}^{2}$ & $\mathbf{x}$ & $\mathbf{x}$ & $\mathbf{x}$ & $\mathbf{x}$ & $\mathbf{x}$ \\
\hline Alite & $\mathbf{x}$ & $\mathrm{x}$ & $x$ & $\mathbf{x}$ & $\operatorname{tr}$ \\
\hline Belite & $\mathbf{x}$ & $\mathbf{x}$ & $\mathbf{x}$ & $\mathbf{x}$ & $\mathbf{x}$ \\
\hline $\begin{array}{l}\text { Aluminoferrite solid solution } \\
\text { Calcite }\end{array}$ & $\begin{array}{l}x \\
t r\end{array}$ & $\begin{array}{l}x \\
t r\end{array}$ & $\begin{array}{l}x \\
t r\end{array}$ & $x$ & $\mathbf{x}$ \\
\hline
\end{tabular}

NOTES: $t r=$ trace; $t r ?=$ possible trace.

Laboratories Reporting Each Constituent

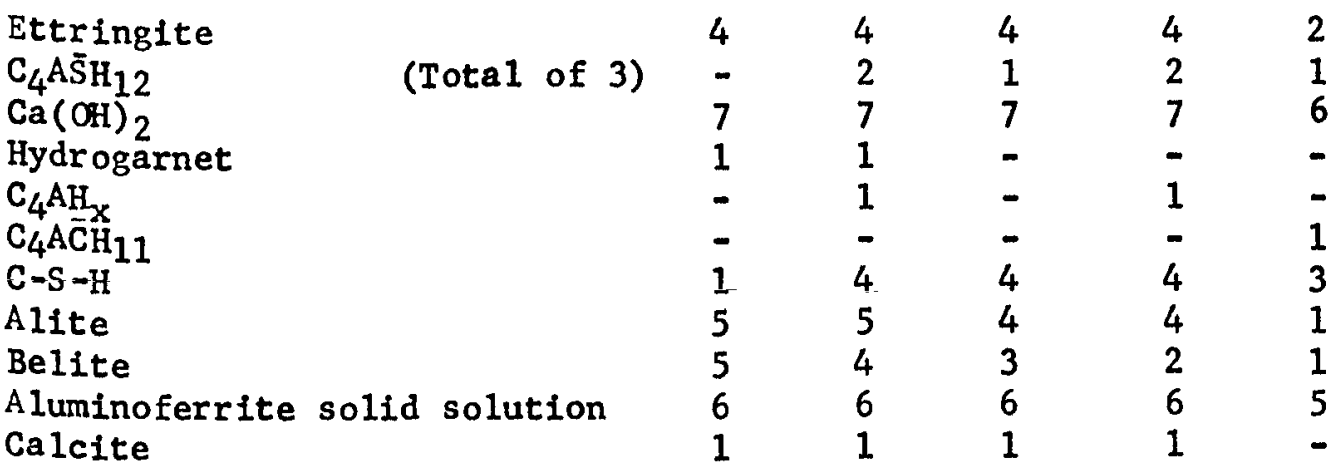


Table 12

Intensity Relations Among Some Constituents of Pastes of 0.65 Water-Cement Ratio(I)

Peak Height Above Background, Counts/Second

\begin{tabular}{lll}
\multicolumn{4}{c}{ Age, Days } \\
\hline 1 & 28 & 90 \\
\hline
\end{tabular}

Cement No. 1 - Type 1

Ettringite

$\mathrm{C}_{4} \mathrm{AS} \mathrm{H}_{12}$

$\mathrm{C}_{4} \mathrm{ACH}_{11}$ (Note 2)

$\mathrm{CH}$

Cement No. 2 - White

Ettringite

$\mathrm{C}_{4} \mathrm{~A} \overline{\mathrm{S}} \mathrm{H}_{12}$

$\mathrm{C}_{4} \mathrm{ACH}_{11}$

$\mathrm{CH}$

Cement No. 3 - Zero $\mathrm{C}_{3} \mathrm{~A}$

Ettringite

$\mathrm{C}_{4} \mathrm{~A} \bar{S}_{12}$

$\mathrm{CH}$

$\begin{array}{rr}47 & 28 \\ - & 26 \\ - & \operatorname{tr} ? \\ 653 & 848\end{array}$

18

39

tr

692 $\operatorname{tr}$ (est)

74

$\mathrm{pr}$

842

(1) Determined by scaling peak heights and adjoining background with diffraction conditions as follows: $50 \mathrm{KV} C P$ and $21 \mathrm{ma}$, Cu radiation with Ni filter, $1^{\circ}$ Beam Slit, $3^{\circ}$ BS as Soller, $0.2^{\circ}$ detector slit, full scale deflection of chart 1000 counts, linear rate meter operation, time constant $8 \mathrm{sec}$, December 1966. Peaks scaled were $9.7 \mathrm{~A}$ (ettringite),

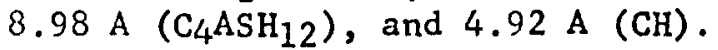

(2) $\mathrm{C}_{4} \mathrm{ACH}{ }_{11}$ was not scaled but its presence is noted as trace, possible trace, or present. 
Sample 35: Hydrated Alite Cured 5.3 Years

Laboratory 3

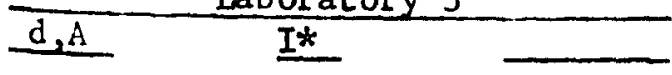

4.92

3.114

3.066

2.786

2.629

1.926

1.819

1.796

1.686

1.635

1.554

1.483

1.449
83

28

12

5
100

43

5

29

15

1

2

7

7
CHI

$\mathrm{CH}$

$\mathrm{C}-\mathrm{S}-\mathrm{H}$ ***

$\mathrm{C}-\mathrm{S}-\mathrm{H}$

$\mathrm{CH}$

$\mathrm{CH}$

C-S - H $2+2 *$

$\mathrm{CH}$

$\mathrm{CH}$

$\mathrm{CH}$

$\mathrm{CH}$

$\mathrm{CH}$

$\mathrm{CH}$
Laboratory 6

\begin{tabular}{lll}
\hline $\mathrm{d}_{2} \mathrm{~A}$ & $\mathrm{I}$ & \\
\hline 4.9 & $\mathrm{vs}$ & $\mathrm{CH}$ \\
3.12 & $\mathrm{~ms}$ & $\mathrm{CH}$ \\
3.07 & $\mathrm{~m} / \mathrm{b}$ & $\mathrm{C}-\mathrm{S}-\mathrm{H}$
\end{tabular}

$2.98 \quad$ VVw $\quad$ C-S $-\mathrm{H}$

2.83

2.63

2.46

vvw

?

vvs $\mathrm{CH}$

VWw $\quad \mathrm{CH}$

\subsection{3}

1.83

1.80

1.69

1.64

vs

w

vs

$s$

vw

$\mathrm{CH}$

$\mathrm{C}-\mathrm{S}-\mathrm{H}$

$\mathrm{CH}$

$\mathrm{CH}$

$\mathrm{CH}$

1.56

m

$\mathrm{CH}$

* Net peak height referred to net height of most intense peak as 100 .

*** Hump from 26 to 38 two-theta, falling off steeply from $29 . \overline{3}$ to 28 two-theta.

twk- About 2.5 two-theta wide at the base. 
Sample 36: Hydrated $\mathrm{B}-\mathrm{C}_{2} \mathrm{~S}$ Cured 5.3 Years

Laboratory 3

\begin{tabular}{|c|c|c|c|c|c|}
\hline \multicolumn{3}{|c|}{ Lab } & \multicolumn{3}{|c|}{ Laboratory 6} \\
\hline$d, A$ & I* & & $\mathrm{d}, \mathrm{A}$ & $I$ & \\
\hline 4.91 & 100 & $\mathrm{CH}$ & 4.91 & ms & $\mathrm{CH}$ \\
\hline 4.64 & 1 & $\beta-C_{2} S$ & & & \\
\hline 3.23 & 2 & $B-C_{2} S$ & 3.34 & vw & $\mathrm{C}_{2} \mathrm{~S}$ \\
\hline 3.11 & 16 & $\mathrm{CH}$ & 3.11 & $\mathrm{~ms}$ & $\mathrm{CH}$ \\
\hline 3.052 & 31 & $\mathrm{C}-\mathrm{S}-\mathrm{H}, \mathrm{CaCO}_{3}$ ?** & 3.06 & $\mathrm{~ms} / \mathrm{b}$ & $\mathrm{C}-\mathrm{S}-\mathrm{H}$ \\
\hline 2.966 & 21 & & 2.97 & $\mathrm{w} / \mathrm{b}$ & $\mathrm{C}-\mathrm{S}-\mathrm{H}$ \\
\hline 2.877 & 16 & $\beta-C_{2} S$ & 2.88 & $\mathrm{mw}$ & $\mathrm{c}_{2} \mathrm{~S}$ \\
\hline 2.815 & 17 & $?$ & & & \\
\hline 2.781 & 21 & $\beta-C_{2} S$ & 2.79 & $\mathbf{m}$ & $\mathrm{C}_{2} \mathrm{~S}, \mathrm{C}-\mathrm{S}-\mathrm{H}$ \\
\hline 2.739 & 19 & $B-C_{2} S$ & 2.75 & w & $c_{2} s$ \\
\hline 2.720 & 10 & $\beta-C_{2} s$ & & & \\
\hline 2.627 & 60 & $\mathrm{CH}$ & 2.63 & vvs & $\mathrm{CH}$ \\
\hline & & & 2.61 & w & $\mathrm{C}_{2} \mathrm{~S}$ \\
\hline 2.547 & 2 & $B-C_{2} S$ & & & \\
\hline 2.442 & 4 & $\beta-\mathrm{C}_{2} \mathrm{~S}, \mathrm{CH}$ & 2.44 & $\mathbf{w}$ & $\mathrm{CH}, \mathrm{C}_{2} \mathrm{~S}$ \\
\hline 2.404 & 4 & $\beta-C_{2} S$ & 2.41 & vw & $\mathrm{C}-\mathrm{S}-\mathrm{H}, \mathrm{C}_{2} \mathrm{~S}$ \\
\hline 2.279 & 3 & $B-C_{2} S$ & 2.28 & $\mathbf{w}$ & $\mathrm{C}_{2} \mathrm{~S}$ \\
\hline 2.189 & 7 & $\beta-c_{2} s$ & 2.19 & $\mathrm{mw}$ & $\mathrm{C}_{2}^{2} \mathrm{~S}$ \\
\hline 2.164 & 2 & $B-C_{2}^{2} S$ & 2.165 & ww & $\mathrm{C}_{2} \mathrm{~s}$ \\
\hline 2.130 & 1 & $B-C_{2} S$ & & & \\
\hline 2.088 & 2 & $3-c_{2}^{2} s$ & 2.08 & vvw & $\mathrm{C}_{2} \mathrm{~S}$ \\
\hline & & & 2.05 & vvw & $\mathrm{C}_{2} \mathrm{~s}$ \\
\hline 2.026 & 3 & $\beta-C_{2} S$ & & & \\
\hline 1.984 & 4 & $\beta-\mathrm{C}_{2}^{2} \mathrm{~S}, \mathrm{CH}$ & 1.98 & vw & $\mathrm{C}_{2} \mathrm{~S}$ \\
\hline 1.926 & 23 & $\mathrm{CH}$ & 1.93 & $\mathrm{~ms}$ & $\mathrm{CH}$ \\
\hline 1.894 & 2 & $\beta-C_{2} S$ & & & \\
\hline 1.819 & 12 & $\mathrm{C}-\mathrm{S}-\mathrm{H} *-* *$ & 1.825 & $\mathrm{~ms} / \mathrm{b}$ & $C-S-H$ \\
\hline 1.796 & 9 & $\mathrm{CH}$ & 1.799 & $\mathbf{s}$ & $\mathrm{CH}$ \\
\hline 1.707 & 1 & $\beta-C_{2} S$ & & & \\
\hline 1.685 & 6 & $\mathrm{CH}$ & 1.69 & $\mathrm{~m}$ & $\mathrm{CH}$ \\
\hline 1.627 & 1 & $\beta-C_{2} S$ & 1.628 & w & $\mathrm{CH}$ \\
\hline 1.549 & 2 & $\beta-C_{2} s$ & & & \\
\hline 1.524 & 2 & $3-c_{2} s$ & & & \\
\hline 1.482 & 3 & $\mathrm{CH}$ & & & \\
\hline 1.448 & 3 & $\mathrm{CH}$ & & & \\
\hline
\end{tabular}

* Net peak height referred to net peak height of strongest peak as 100 . * Halo from 26 to 38 two-theta. wer Abcut 2 two-theta wide at base. 
Table 15

Samp 1e 37: Tetracalcium Aluminate Hemicarbonate-12-Hydrate

Laboratory 5

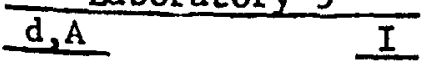

8.12

5.405

5.12

4.895

4.104

3.878

3.359

3.245

3.134

2.88

2.808

2.728

2.549

2.448

2.358

2. 319

2.293

2.166

2.043

1.985

1.939

1.771

1.75

1.663

1.635 vvs

vw
$w$
$w$

vs

S

w

vw

vw

m

w

m

m

m

m

w

ms

3.13

3.02

2.88

2.83

2.80

2.72

2.62

2.54

2.47

2.44

2.35

2.31

2.29

2.22

2.20

2.16

2.07

2.03

1.98

1.94

1.88

1.86

1.85

1.80

1.78

1.75

1.74

1.70

1.68

1.67

1.66

1.63
Laboratory 6

10

1

?

$\mathrm{C}_{3} \mathrm{AH}_{6}$

$\mathrm{C}_{3} \mathrm{AH}_{6}$

$\mathrm{C}_{3} \mathrm{AH}_{6}$

$\mathrm{C}_{3} \mathrm{AH}_{6}$

$\mathrm{C}_{3} \mathrm{AH}_{6}$

$\mathrm{C}_{3} \mathrm{AH}_{6}$ ?

$\mathrm{C}_{3} \mathrm{AH}_{6}$

$\mathrm{C}_{3} \mathrm{AH}_{6}$ ?

$\mathrm{C}_{3} \mathrm{AH}_{6}$ ?

$\mathrm{C}_{3} \mathrm{AH}_{6}$ 
Samp le 38: Tetracalclum Aluminate Carbonate-11-Hydrate

Laboratory 3

d,A I*

7.62

5.71

5.14

4.98

4.85

4.68

4.49

4.36

3.99

3.79

3.65

3.46

3.36

3.30

3.144

3.03

2.859

2.779

$-2.725$

2.654

2.576

2.526

2.490

2.444

2.422

2. 340

2.294

2.239

2.214

2. 167

2.140

2.118

2.099

2.065
100

$<1$

$<1$

$<1$
1

$<1$

1

2

2

47

1

3

$<1$

$<1$

$<1$

$<1$
7

2

4

1

$<1$

9

5

3

12

11

2

1

$<1$

$<1$
5

5

$<1$
$\mathrm{C}_{3} \mathrm{AH}_{6}$
Laboratory 6

d,A I

7.6

5.72

5.12

4.94

4.88

4.82

Bayerite?

4.66

4.46

4.34

3.97

3.81

3.80

3.64

3.45

3.40

3.34

3.29

3.13

2.86

2.85

2.82

2.81

2.78

2.73

2.65

2.62

2.58

2.53

2.52

2.49

2.48

2.44

2.42

2.33

2.29

2.26

2.23

2.21

2.165]

$2.16]$

2.13

2.11

2.09

2.06
10

1

2

1

$\mathrm{C}_{3} \mathrm{AH}_{6}$

$\mathrm{C}_{3} \mathrm{AH}_{6}$ ?

$\mathrm{C}_{3} \mathrm{AH}_{6}$

$\mathrm{C}_{3} \mathrm{AH}_{6}$

$\mathrm{C}_{3} \mathrm{AH}_{6}$

5

7

1

1

2

7

2

6

7

6

8

8

$3 \quad \mathrm{C}_{3} \mathrm{AH}_{6}$ ?

1

3

3

1

3

2

5

3

2

* Intensity expressed as net peak height referred to height of 7.62-A peak. 
Table 16 (Continued)

Laboratory 3

\begin{tabular}{|c|c|c|c|c|c|}
\hline & & & & & \\
\hline $\mathrm{d}, \mathrm{A}$ & $I *$ & & $d, A$ & $I$ & \\
\hline 2.036 & 2 & $\mathrm{C}_{3} \mathrm{AH}_{6}$ in part? & 2.03 & 2 & \\
\hline 2.028 & 2 & & 2.02 & 1 & $\mathrm{C}_{3} \mathrm{AH}_{6}$ \\
\hline 2.013 & 3 & & 2.01 & 3 & \\
\hline 1.992 & $<1$ & & 1.99 & 2 & \\
\hline 1.946 & 6 & & 1.94 & 4 & \\
\hline & & & 1.93 & 2 & \\
\hline 1.906 & $<1$ & & 1.90 & 2 & \\
\hline 1.892 & 1 & & 1.88 & 2 & \\
\hline 1.861 & 3 & & 1.86 & 4 & \\
\hline & & & 1.83 & 1 & \\
\hline 1.824 & 4 & & 1.82 & 4 & \\
\hline 1.796 & $<1$ & & 1.80 & 1 & \\
\hline & & & 1.77 & 1 & \\
\hline 1.751 & $<1$ & & 1.75 & 1 & \\
\hline 1.745 & $<1$ & $\mathrm{C}_{3} \mathrm{AH}_{6}$ & 1.74 & 1 & \\
\hline 1.728 & $<1$ & & 1.72 & 1 & \\
\hline 1.714 & 1 & & 1.71 & 1 & \\
\hline 1.690 & $<1$ & & 1.69 & 1 & \\
\hline 1.679 & $<1$ & $\mathrm{C}_{3} \mathrm{AH}_{6}$ & 1.68 & 1 & \\
\hline 1.665 & 2 & & 1.67 & 1 & $\mathrm{C}_{3} \mathrm{AH}_{6}$ \\
\hline & & & $\begin{array}{l}1.66 \\
\text { and } f\end{array}$ & $s^{5} t$ & \\
\hline
\end{tabular}

* Intensity expressed as net peak height referred to height of 7.62-A peak. 
Sample 39: Tetracalcium Aluminate Monosu1fate-12-Hydrate

Laboratory 3

\begin{tabular}{|c|c|}
\hline $\mathrm{d}, \mathrm{A}$ & $I *$ \\
\hline 9.8 & 2 \\
\hline 8.96 & 100 \\
\hline 5.60 & $<1$ \\
\hline 4.90 & 1 \\
\hline 4.68 & $<1$ \\
\hline 4.47 & 32 \\
\hline 4.00 & 12 \\
\hline 3.88 & $<1$ \\
\hline 3.65 & 1 \\
\hline 3.47 & $<1$ \\
\hline 3.24 & $<1$ \\
\hline 3.031 & $<1$ \\
\hline 2.879 & 6 \\
\hline 2.778 & 1 \\
\hline 2.741 & 3 \\
\hline 2.615 & $<1$ \\
\hline 2.559 & $<1$ \\
\hline 2.479 & $<1$ \\
\hline 2.449 & 4 \\
\hline 2.421 & 8 \\
\hline 2.362 & 4 \\
\hline 2.336 & 2 \\
\hline 2.260 & 1 \\
\hline 2.236 & 2 \\
\hline 2.189 & 4 \\
\hline 2.149 & $<1$ \\
\hline 2.088 & 1 \\
\hline 2.072 & 6 \\
\hline 2.000 & 1 \\
\hline 1.905 & 2 \\
\hline 1.879 & $<1$ \\
\hline 1.867 & $<1$ \\
\hline 1.825 & 3 \\
\hline 1.816 & 1 \\
\hline 1.788 & $<1$ \\
\hline 1.765 & 1 \\
\hline 1.742 & $<1$ \\
\hline 1.691 & $<1$ \\
\hline 1.661 & 2 \\
\hline 1.634 & 1 \\
\hline
\end{tabular}

Laboratory 6

d,A I I

$\begin{array}{rr}9.8 & 1 \\ 9.0 & 10\end{array}$

5.62

4.92

4.70

4.48

4.00

3.88

3.66

3.48

2.88

2.78

2.74

2.63

2.56

2.48

2.45

2.42

2.36

2.34

2.26

2.24

2.20

2.19

2.15

2.09

2.07

2.00

1.91

1.88

1.87

1.83

1.81

1.78

1.77

1.74

1.69

1.66

1.64

1.63
Ettringite

1

10

1

1

8

9

1

3

$1 \quad$ E

E

E

E

E?

E

E

E

E

$\mathrm{E}$
$\mathrm{E} ?$
$\mathrm{E} ? \mathrm{E}$ or $\mathrm{Ca}(\mathrm{OH})_{2}$ ?

$$
E
$$

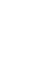




\section{Table 17 (Continued)}

Laboratory 3

\begin{tabular}{lrr}
\hline$d, A$ & & I* \\
\cline { 1 - 1 } & & \\
1.589 & & 2 \\
1.558 & & $<1$ \\
1.544 & & $<1$ \\
1.522 & & $<1$ \\
1.504 & & $<1$ \\
1.492 & & $<1$ \\
1.454 & & $<1$ \\
1.439 & & $<1$ \\
1.422 & & $<1$ \\
1.392 & & 2
\end{tabular}

Laboratory 6

\begin{tabular}{cc}
\hline$d, A$ & $I$ \\
1.59 & 2 \\
1.56 & 3 \\
1.54 & 3 \\
& \\
1.49 & 2 \\
1.45 & 1 \\
1.44 & 3 \\
1.42 & 2 \\
1.39 & 2 \\
1.38 & 1 \\
1.37 & 2 \\
1.35 & 2
\end{tabular}

* Intensity expressed as net peak height referred to net peak height of 8.96 A peak. 
Table 18

Unstable $\mathrm{C}_{4} \mathrm{AH}_{10.5}$

Lab oratory 1

$\mathrm{d}, \mathrm{A}$ I

$7.91 \quad 100 \quad \mathrm{C}_{4} \mathrm{AH}_{13}$

$7.607 \mathrm{M}$

$\begin{array}{ll}5.13 & 2 \\ 4.91<1 & \mathrm{C}_{3} \mathrm{AH}_{6}\end{array}$

$4.44<1 \quad \mathrm{C}_{3} \mathrm{AH}_{6}$

$3.96 \quad 22 \quad \mathrm{C}_{4} \mathrm{AH}_{13}$

$3.782 \mathrm{M}$

$3.36 \quad 1 \quad \mathrm{C}_{3} \mathrm{AH}_{6}$

$2.81 \quad 1 \quad \mathrm{C}_{3} \mathrm{AH}_{6}$

2.64

$1 \mathrm{CH}$

$\mathrm{CH}$

Laboratory 3

d,A I

$8.20100 \mathrm{H}$

$5.25<1$

$\begin{array}{lll}5.12 & 16 & \mathrm{C}_{3} \mathrm{AH}_{6} \\ 4.89 & 28 & \mathrm{CH}\end{array}$

$4.62<1 \quad \mathrm{H}$

4.43

$7 \mathrm{C}_{3} \mathrm{AH}_{6}$

$4.09 \quad 28 \quad \mathrm{H}$

$3.86 \quad 4 \quad \mathrm{H}$

3.50

$<1 \quad H$

$\begin{array}{lll}3.348 & 8 & \mathrm{C}_{3} \mathrm{AH}_{6}\end{array}$

3.248

3.136

3.11

$<1$

$6 \mathrm{C}_{3} \mathrm{AH}_{6}$

$2 \mathrm{CH}$

$2.87 y$

2

2.806

$12 \mathrm{C}_{3} \mathrm{AH}_{6}$

2.712

2.676

$1 \mathrm{H}$

2.624

$1 \mathrm{C}_{3} \mathrm{AH}_{6}$

$2.562 \quad 3 \quad \mathrm{C}_{3} \mathrm{AH}_{6}$

$2.540 \quad 2 \mathrm{H}$

$2.47 \quad 1 \quad \mathrm{C}_{3} \mathrm{AH}_{6}$

2.460

2.443

$5 \mathrm{C}_{3} \mathrm{AH}_{6}$

3 H, $\mathrm{H}$

$2.302 \mathrm{C}_{3} \mathrm{AH}_{6}$

$2.290 \quad 16 \quad \mathrm{C}_{3} \mathrm{AH}_{6}$

2.210

2.161

2.116

$<1$ H

$$
<1
$$

Laboratory 5

d,A I

8.19 ss H

7.81 s $\mathrm{C}_{4} \mathrm{~A}_{0 .} \overline{\mathrm{C}}_{0} \mathrm{H}_{10}$

$\begin{array}{lll}5.13 & \mathrm{~s} & \mathrm{C}_{3} \mathrm{AH}_{6} \\ 4.91 & \mathrm{~s} & \mathrm{CH}\end{array}$

4.785 wW H

$4.440 \mathrm{~m} \quad \mathrm{C}_{3} \mathrm{AH}_{6}$

$4.105 \mathrm{~s} \quad \mathrm{H}$

$3.870 \mathrm{~b} \quad \mathrm{H}$

$3.336 \mathrm{~m} \quad \mathrm{C}_{3} \mathrm{AH}_{6}$

$3.140 \quad w \quad \mathrm{C}_{3} \mathrm{AH}_{6}$

3.115 w $\mathrm{CH}$

2.880 WW H

$2.813 \mathrm{~m} \quad \mathrm{C}_{3} \mathrm{AH}_{6}$

2.731 wwb

2.682 WW

$2.629 \mathrm{~m} \mathrm{CH} H$

2.571 w $\mathrm{C}_{3} \mathrm{AH}_{6}$

$2.469 w \quad \mathrm{c}_{3} \mathrm{AH}_{6}$

$2.298 \mathrm{~m} \quad \mathrm{C}_{3} \mathrm{AH}_{6}$

2.209 b $\quad \mathrm{C}_{3} \mathrm{AH}_{6}$

$\begin{array}{lll}2.04 & 2 & \mathrm{C}_{3} \mathrm{AH}_{6} \\ 1.98 & 1 & \mathrm{C}_{3} \mathrm{AH}_{6}\end{array}$

$\begin{array}{lrl}2.036 & 15 & \mathrm{C}_{3} \mathrm{AH}_{6}, \mathrm{H} \\ 1.984 & 2 & \mathrm{C}_{3} \mathrm{AH}_{6}, \mathrm{H} \\ 1.922 & 5 & \mathrm{CH} \\ 1.859 & <1 & \mathrm{H}\end{array}$

$2.040 \mathrm{~s}$

$1.987 \mathrm{Ww}$

1.926

w

$\mathrm{C}_{3} \mathrm{AH}_{6}, \mathrm{H}$

$\mathrm{C}_{3} \mathrm{AH}_{6}, \mathrm{H}$

$1.859<1 \quad \mathrm{H}$

NOTF: $\mathrm{H}=\mathrm{C}_{4} \mathrm{AC}_{0} .5^{\mathrm{H}_{12}} ; \mathrm{M}=\mathrm{C}_{4} \mathrm{AC} \mathrm{CH}_{12}$. References: H. F. W. Taylor, The Chemistry of Cements, Vo1 2, pp 394-396; cards 3-125, 4-733, Joint Committee on Powder Diffraction Standards; M. H. Roberts, Calcium Aluminate Hydrates and Related Basic Salt Solid Solutions, 5th Int Symposium on the Chemistry of Cements, Tokyo, 1968, Vol 2, 106. 
Table 18 (Continued)

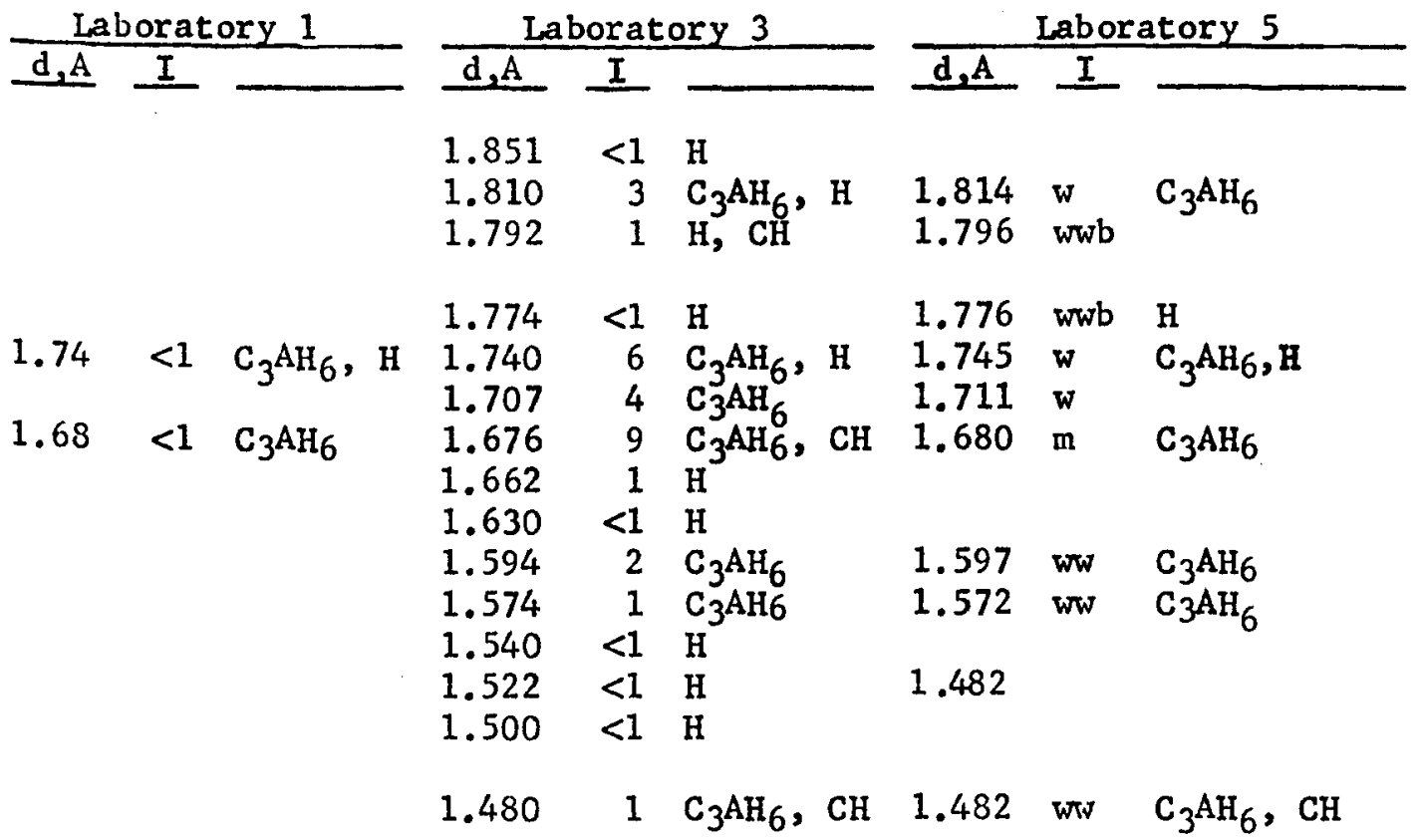


Table 19

\section{Sample 41: Ettringite}

Laboratory 3

\begin{tabular}{|c|c|c|c|c|}
\hline & & & \\
\hline $\mathrm{d}, \mathrm{A}$ & $I^{*}$ & & $\mathrm{~d}, \mathrm{~A}$ & $\bar{I}$ \\
\hline 10.72 & 2 & $\mathrm{Cu} \mathrm{K}_{B}$ of 9.75 & 11.0 & 2 \\
\hline 9.75 & 100 & & 9.8 & 10 \\
\hline 8.84 & 9 & & 8.9 & 4 \\
\hline 7.19 & 1 & Not ettringite & 7.2 & 2 \\
\hline 5.79xis & 4 & & 5.81 & 3 \\
\hline 5.62 & 50 & & 5.63 & 8 \\
\hline 4.97 & 12 & & 4.99 & 5 \\
\hline 4.86 & 4 & & 4.86 & 2 \\
\hline 4.70 & 18 & & 4.72 & 8 \\
\hline 4.43 & $<1$ & & & \\
\hline 4.02 & 4 & & 4.03 & 3 \\
\hline 3.87 & 28 & & 3.89 & 9 \\
\hline 3.67 & 3 & & 3.68 & 2 \\
\hline 3.60 & 7 & & 3.61 & 5 \\
\hline 3.48 & 17 & & 3.48 & 7 \\
\hline 3.271 & 4 & & 3.27 & 3 \\
\hline 3.241 & 12 & & 3.24 & 5 \\
\hline & & & 3.20 & 1 \\
\hline 3. $108 * x$ & $<1$ & & 3.10 & 1 \\
\hline 3.019 & 4 & & 3.02 & 5 \\
\hline-2.806 & 3 & & 2.81 & 2 \\
\hline 2.774 & 21 & & 2.78 & 9 \\
\hline 2.717 & 1 & & 2.72 & 1 \\
\hline & & & 2.69 & 2 \\
\hline 2.688 & 6 & & 2.68 & 3 \\
\hline 2.612 & 11 & & 2.62 & 5 \\
\hline 2.562 & 18 & & 2.57 & 9 \\
\hline 2.522 & 2 & & 2.52 & 2 \\
\hline 2.485 & 2 & & 2.49 & 3 \\
\hline 2.409 & 5 & & 2.41 & 4 \\
\hline 2.348 & 2 & & 2.35 & 4 \\
\hline & & & 2.32 & 1 \\
\hline & & & 2.28 & 1 \\
\hline 2.229 & 4 & & 2.23 & 4 \\
\hline 2.208 & 21 & & 2.21 & 9 \\
\hline 2.184 & 4 & & 2.18 & 3 \\
\hline 2.151 & 11 & & 2.15 & 7 \\
\hline & & & 2.13 & 1 \\
\hline 2.123 & 3 & & 2.12 & 2 \\
\hline 2.079 & $<1$ & & 2.08 & 2 \\
\hline 2.053 & 2 & & 2.06 & 3 \\
\hline
\end{tabular}

* Intensity expressed as net peak height referred to net peak height of 9.75 A line.

w. Not on card 9-414 of Joint Committee Powder Diffraction File 


\section{Table 19 (Continued)}

\section{Laboratory 3}

\begin{tabular}{ll}
\hline$d, A$ & I \\
2.030 & $<$ \\
2.003 & $<$ \\
1.976 & \\
1.973 & \\
1.943 &
\end{tabular}

Laboratory 6

I*

$<1$

$<1$

1

6

2.01

1.98 2

1.95

1.93

1.91

1.90

1.901

$<1$

1.87

1.86

1.85

I

1.852

5

1.83

1.81

1.80

\section{4}

1.843

3

1.825

1

1.802

1

1.79

1.78

1.76

$1.788<1$

$1.765 \quad 2$

1.75

1.72

1.71

1.68

1.66

1.62

1.61

1.60

1.661

$<1$

1

1.58

1.575

1.57

1.539

2

1.54

1.53

1.52

1.51

1.495

1.49

1.558

$<1$

1.540

$<1$

$<1$

* Intensity expressed as net peak height referred to net peak height of 9.75 A line. 

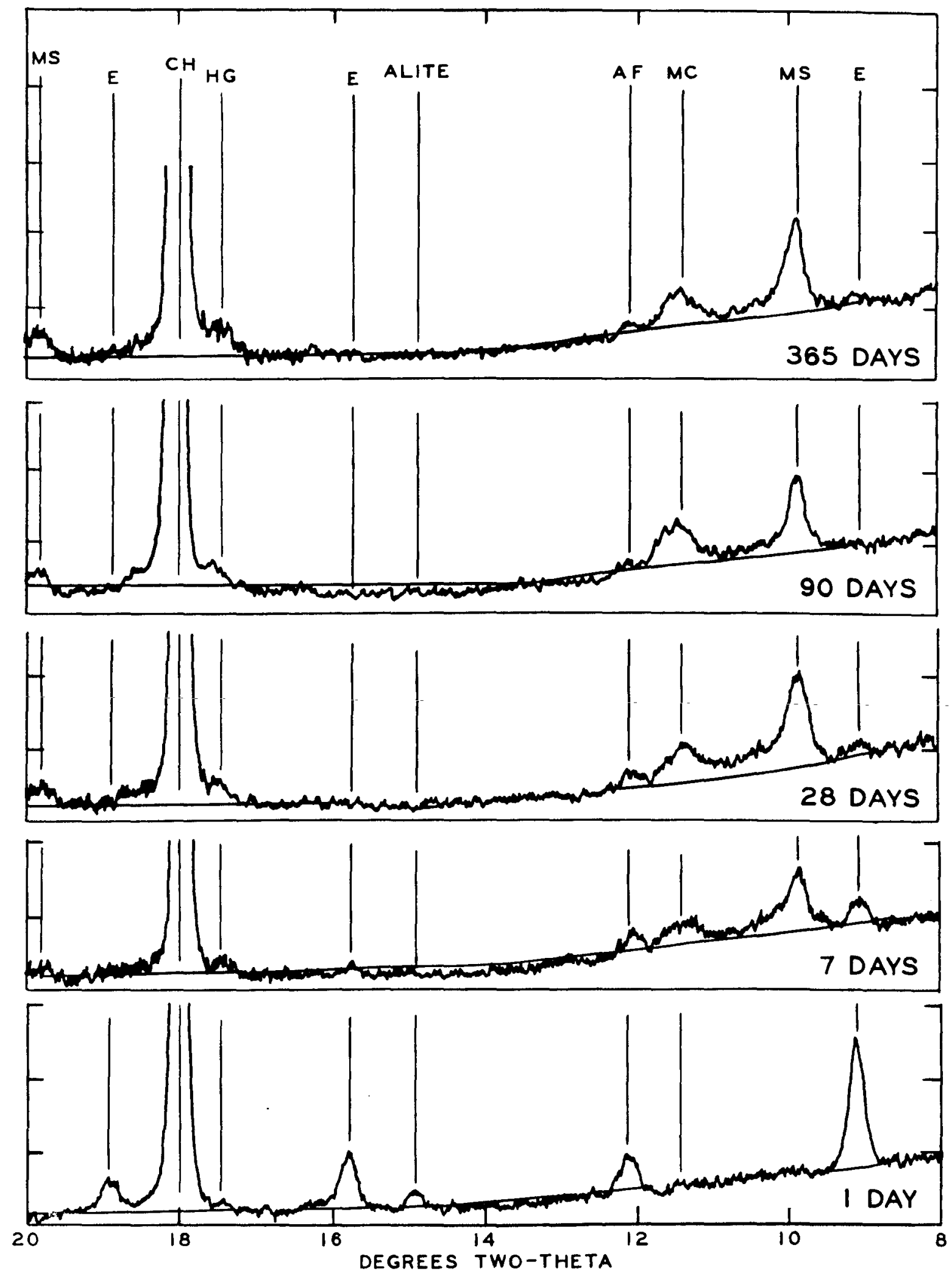

Fimur. 1. Partial diffractometer charts of pastes of $0.65 \mathrm{w} / \mathrm{c}$, cement No. 1 . Beim slit $1^{\circ}, 3^{\circ}$ bam lit as Soller, $0.2^{\circ}$ detector slit, scanning speed $0 . c^{\circ}$ pr minute, linear rate meter operation with full-scale deflection 1000 :oluts ner second, time constant 8 sec; $M S=C_{4} A \bar{S} H_{12} \cdot M C=C_{4} A \bar{C} H_{11}$. $\mathrm{H} r=h_{r} \cdot 1$ rogarnet 

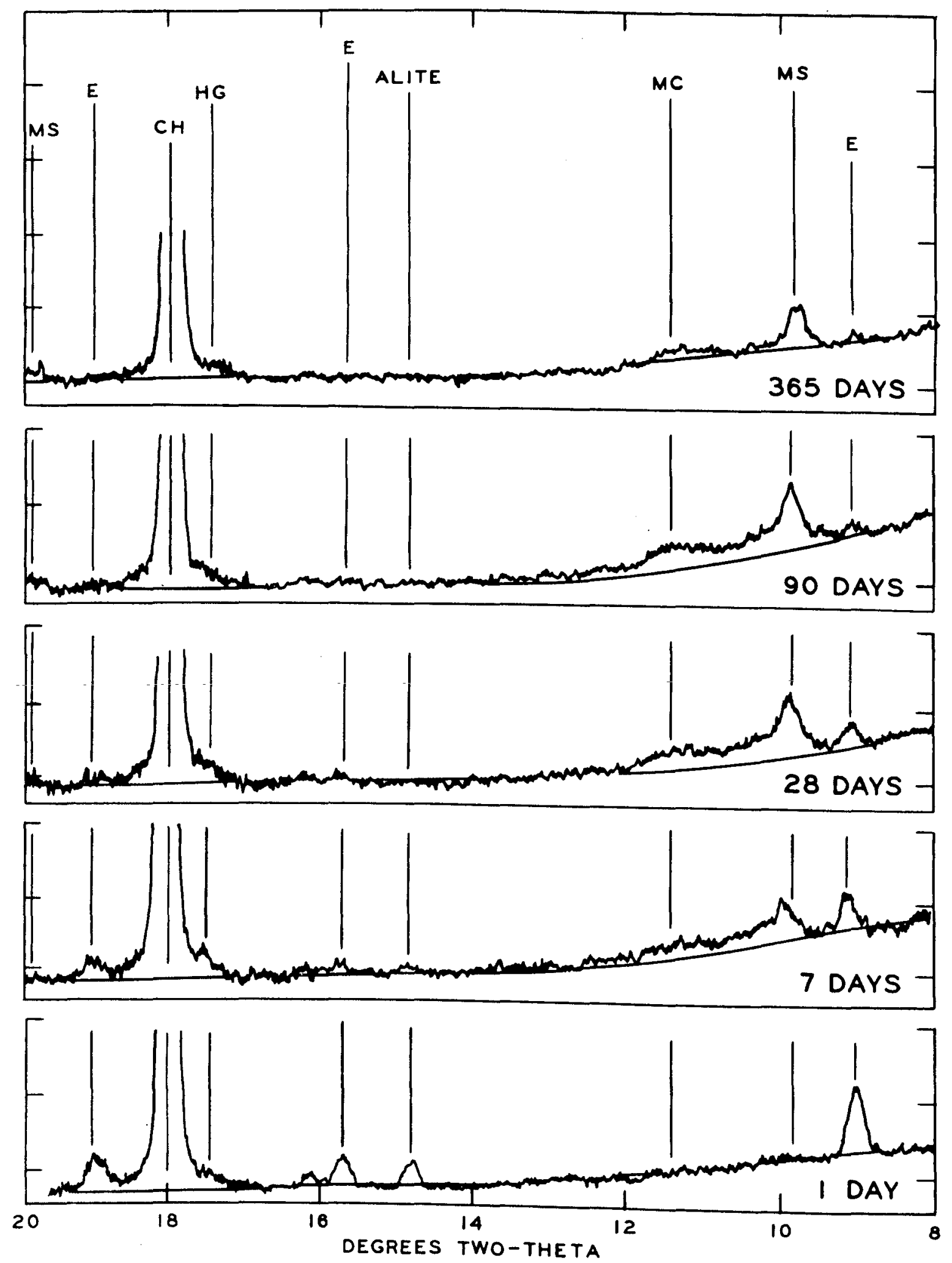

Firure 2. Partial diffractometer charts of pastes of $0.65 \mathrm{w} / \mathrm{c}$, cement No. 2 , as in fig. 1. The hydrogarnet line at 17.5 two-theta is shown but evidence. o." its presence is suggested only at 7 days. The broad indefinite bulge markex $\mathrm{MC}\left(=\mathrm{C}_{4} \overrightarrow{\mathrm{ACH}} \overrightarrow{\mathrm{H}}_{1}\right)$ in charts of 7 through 90 day pasteis covers a range of spasings and alternate identifications could be marte. 

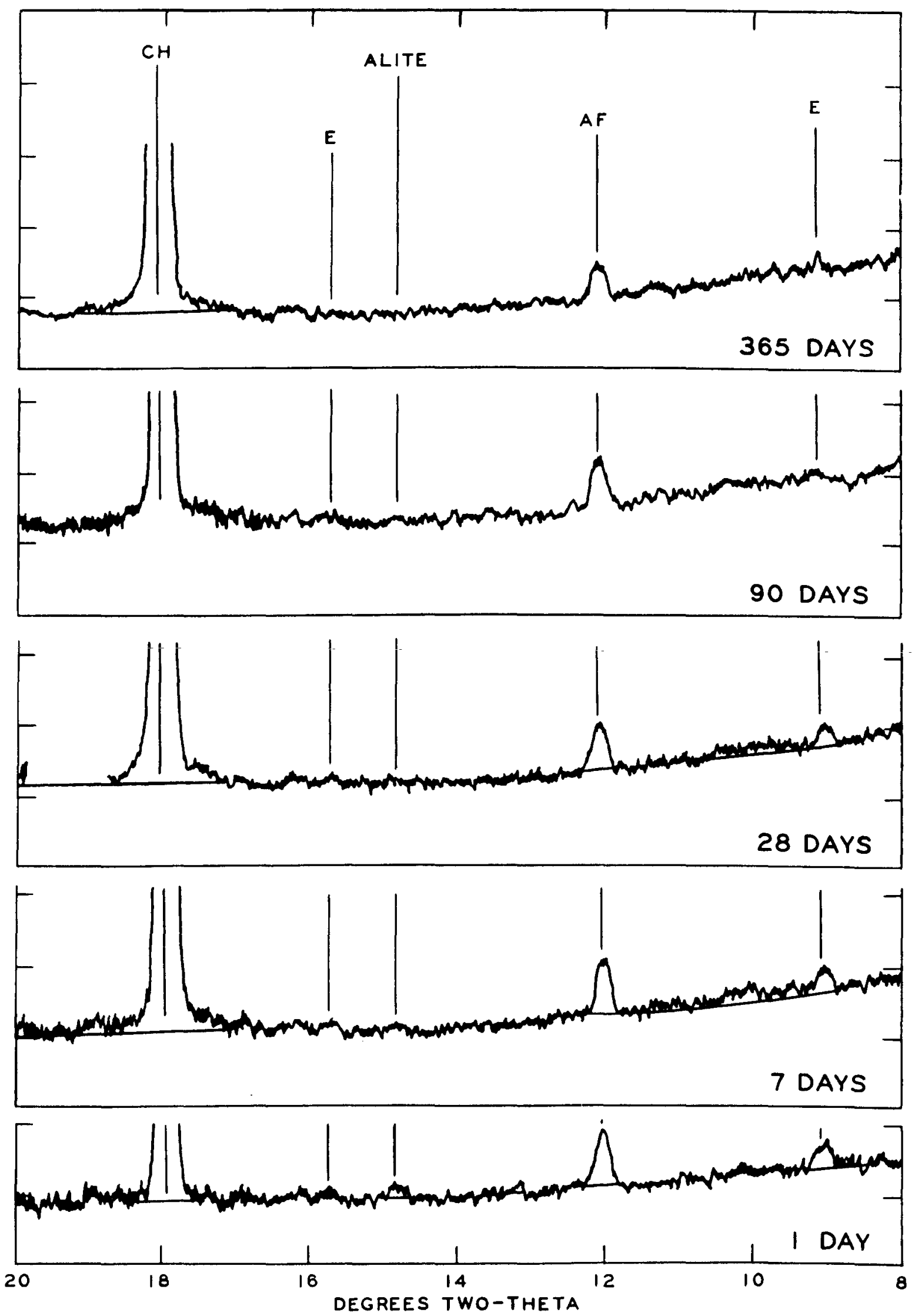

Fisur. 3. Whists of pastes of $0.65 \mathrm{w} / \mathrm{c}$, cement $\mathrm{No} .3$, as in figs. 1 and 2. 


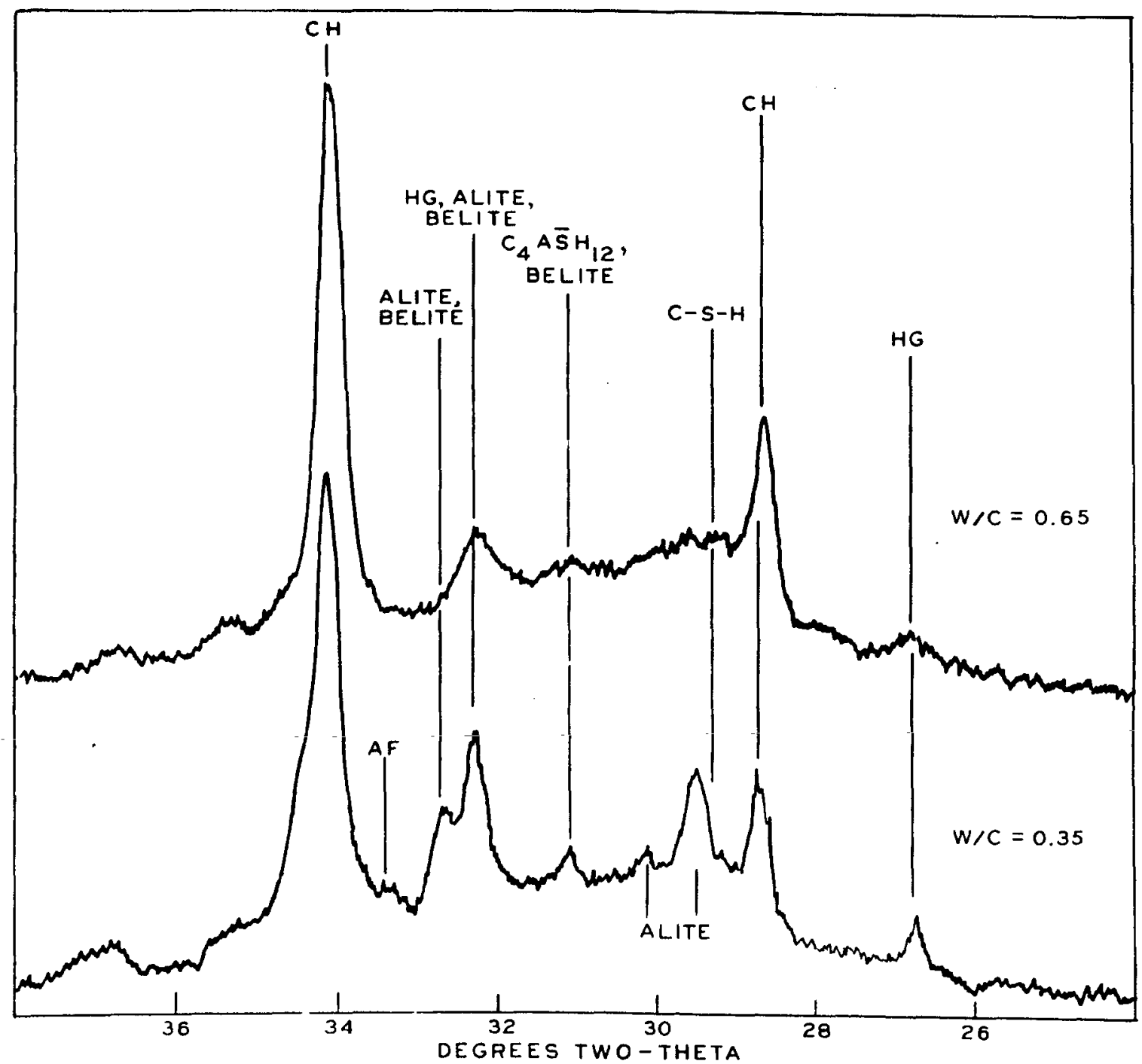

igure 4. Partial diffractometer charts of 365-day pastes, cement No. 1. conditions as in figs. I through 3 except logarithmic rate meter operation ith time constants 30, 7.5, and $2 \mathrm{sec}$ in the first, second, and third decades of the scale. Residual silicates present in $0.35 \mathrm{w} / \mathrm{c}$ paste. 


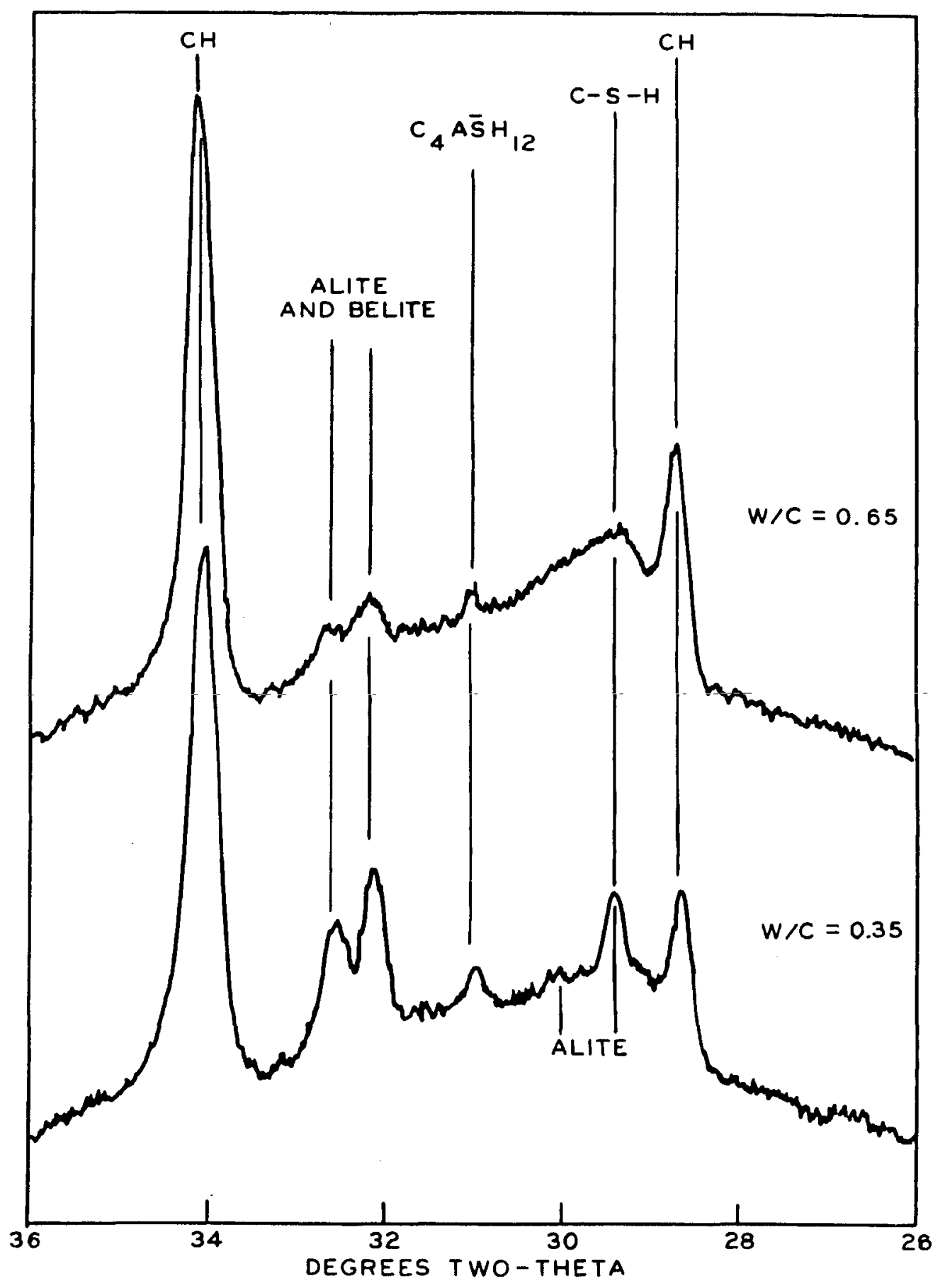

Fifure 5. Charts of 365-day pastes of cement No. 2. Both pasto son ain rom residual silicates. 


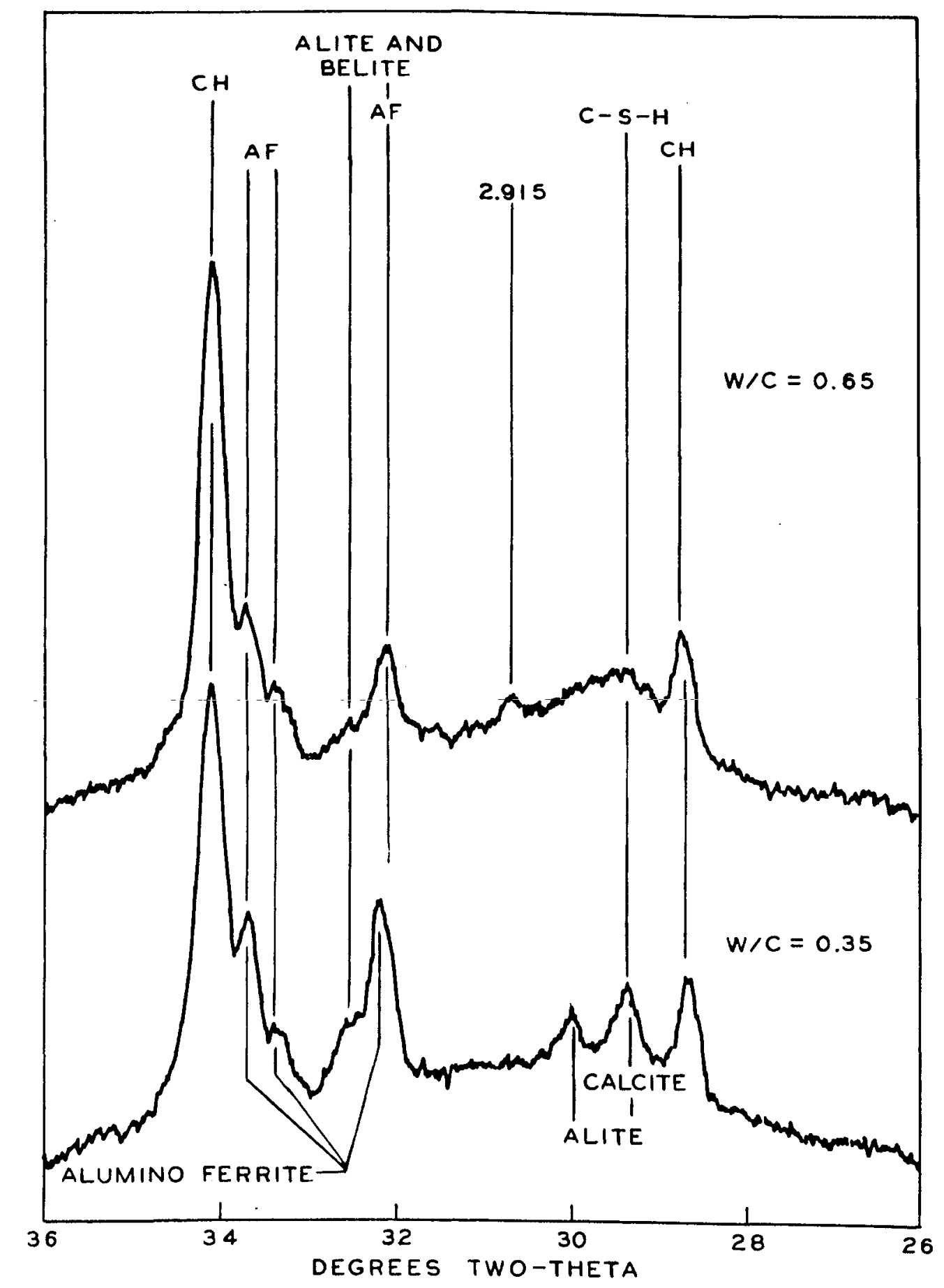

Figure 6. Charts of 365-day pastes of cement No. 3. Strong residual aluminoforrite solid solutions and somo silicates. spacing at 2.915 unidentified. 


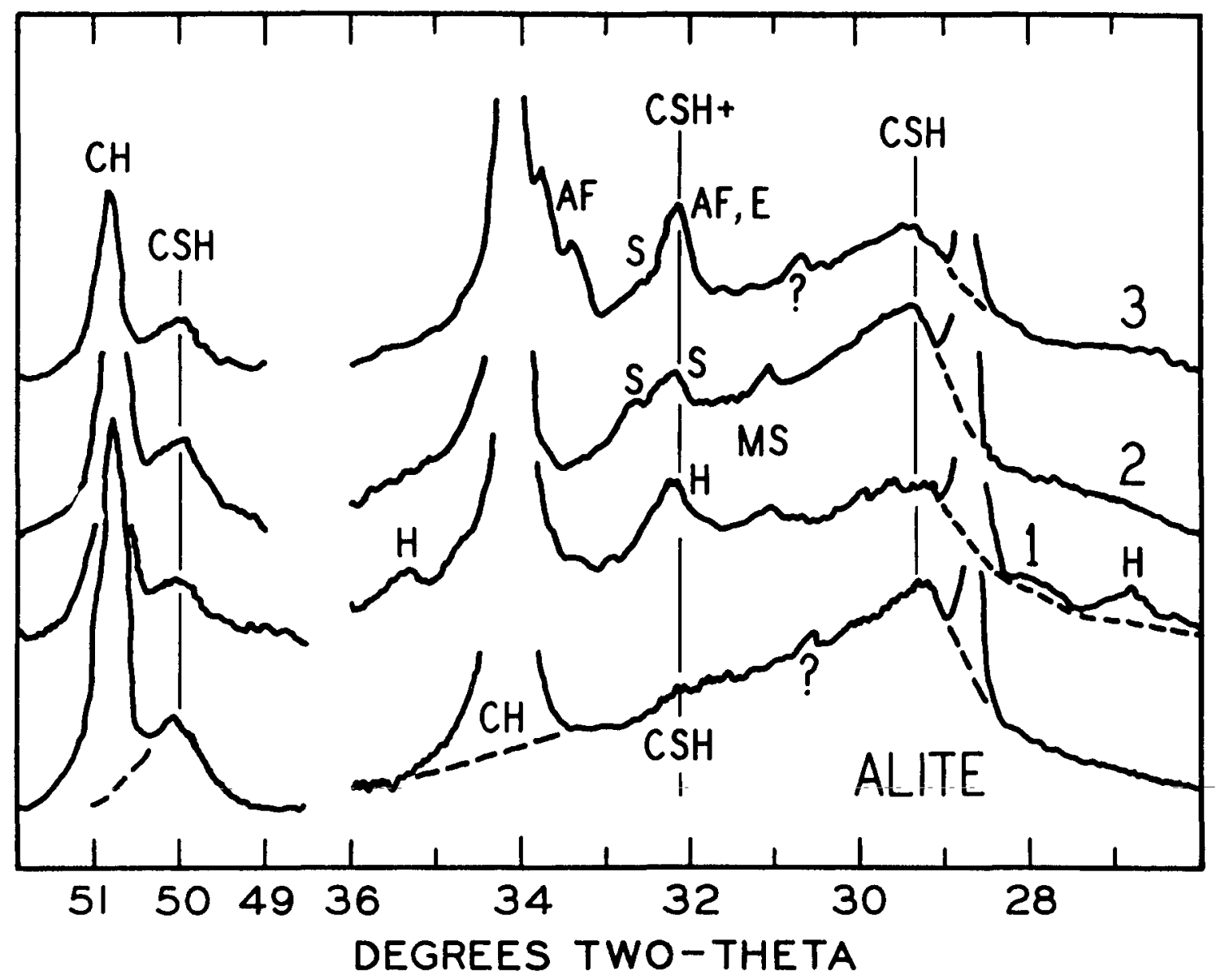

Firure 7. Charts of $0.65 \mathrm{w} / \mathrm{C} 365$-day pastes of all three cements, with 5.3-ycar-hydrated alite as comparison. The alite spacing between $29^{\circ}$ and $30^{\circ}$ appears longer than those of the cements. C $-\mathrm{S}-\mathrm{H}=\mathrm{C}-\mathrm{S}-\mathrm{H}$ gel; $S=$ silicates (alite and belite). 
Unclassilied

\section{DOCUMENT CONTROL DATA - R \& D}

(Security classtlication of tltle, body of abatract and indexing annotation must be entered when the overall report is clacellled) 1. ORIGINA TING ACTIVITY (Comorate euthor)

U. S. Army Engineer Waterways Experiment Station

Vicksburg, Mississippi

20. REPORT SECURITY CLASSIFICATION Unclassified

B. REPOAT TITLE

EXAMINATION OF CEMENT PASTES, HYDRATED PHASES, AND SYNTHETIC PRODUCTS

BY $X$-RAY DIFFRACTION

4. DESCRIPTIVE NOTES (TYPO of repart and Incluatve datee)

Final report

5. AU THOR(S) (Flrat mame, Giddie Initial, laet nome)

Katharine Mather

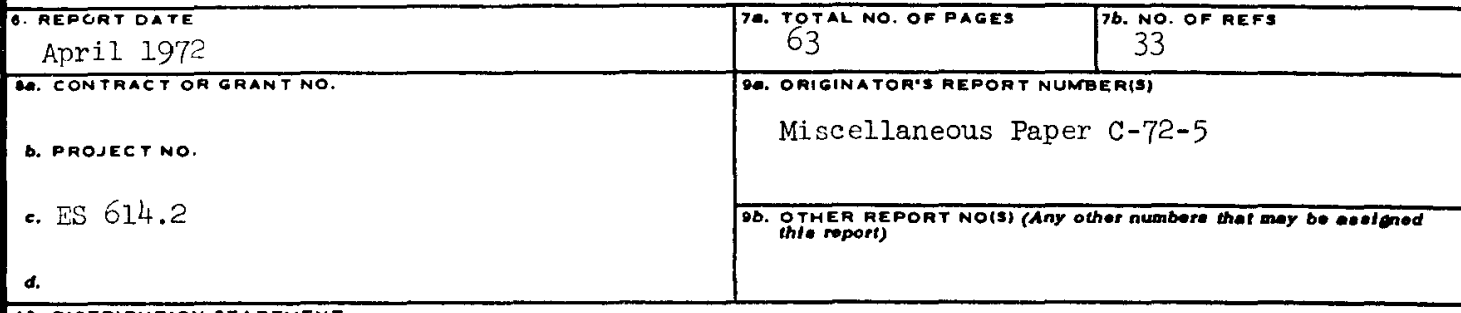

10. DISTRIBUTION STATEMENT

Approved for public release; distribution unlimited.

\begin{tabular}{|c|c|}
\hline 11. SUPPLEMENTAAY NOTES & 12 SRONSORMG-AHLITARY-ACTIVITY \\
\hline & $\begin{array}{l}\text { Office, Chief of Engineers, U. S. Army } \\
\text { Washington, D. C. }\end{array}$ \\
\hline
\end{tabular}

\section{ABSTRACT}

Pastes of three cements were examined by $\mathrm{X}$-ray diffraction at five ages in seven laboratories. Six of the laboratories used X-ray diffractometers and one used a focusing camera of the Guinier type. Six laboratories examined hydrated phases and synthesized hydrates. This is the first cooperative program in X-ray diffraction of portland cement pastes and synthetic hydrates of which we have knowledge. Pastes of all three cements were mixed at water-cement ratios of 0.35 and 0.65 and were examined aftor hydration had been stopped at ages of $1,7,28,90$, and 365 days. Pastes of a Typs I coment at 0.35 water-cement ratio contained ettringite, tetracalcium aluminate monosulfate-12-hydrate, calcium hydroxide, calcium silicate hydrate gel, and residual cement constituents. Tetracalcium aluminate monosulfate-12-hydrate was detected at 7 days and increased thereafter at the expense of ettringite. Compositions of pastes of this cement at 0.65 water-cement ratio were similar to those of the pastes of 0.35 water-cement ratio; the sequences of hydrates appearing and increasing, and cement constituents diminishing and in some instances disappearing, were more conspicuous. The sequence of development and constituents present in pastes of a white cement at the two water-cement ratios resembled the Type I pastes. Pastes of a third comont containing no tricalcium aluminate formed less ettringite than pastes of the other two cements; ettringite persisted to one year; tetracalcium aluminate monosulfate-12-hydrate was detected only in trace anounts. Spacings present in hyHratod alite, hydrated $\beta-C_{2} S$, tetracalcium aluminate hemicarbonate-12-hydrate, tetracalcium aluminate carbonate-11-hydrate, tetracalcium aluminate monosulfate-12-hydrate, unitublo tetracalcium aluminate-10.5-hydrate, and ettringite, are reported. 


$=0$

